\title{
Modeling Molten Salt Reactor Fission Product Removal with SCALE
}

\section{Approved for public release. Distribution is unlimited.}

Pedro Jr. Vicente Valdez Benjamin R. Betzler William A. Wieselquist Massimiliano Fratoni, UC Berkeley

February 2020 


\section{DOCUMENT AVAILABILITY}

Reports produced after January 1, 1996, are generally available free via US Department of Energy (DOE) SciTech Connect.

Website: www.osti.gov

Reports produced before January 1, 1996, may be purchased by members of the public from the following source:

National Technical Information Service

5285 Port Royal Road

Springfield, VA 22161

Telephone: 703-605-6000 (1-800-553-6847)

TDD: $703-487-4639$

Fax: 703-605-6900

E-mail: info@ntis.gov

Website: http://classic.ntis.gov/

Reports are available to DOE employees, DOE contractors, Energy Technology Data Exchange representatives, and International Nuclear Information System representatives from the following source:

Office of Scientific and Technical Information

PO Box 62

Oak Ridge, TN 37831

Telephone: 865-576-8401

Fax: 865-576-5728

E-mail: report@osti.gov

Website: http://www.osti.gov/contact.html

This report was prepared as an account of work sponsored by an agency of the United States Government. Neither the United States Government nor any agency thereof, nor any of their employees, makes any warranty, express or implied, or assumes any legal liability or responsibility for the accuracy, completeness, or usefulness of any information, apparatus, product, or process disclosed, or represents that its use would not infringe privately owned rights. Reference herein to any specific commercial product, process, or service by trade name, trademark, manufacturer, or otherwise, does not necessarily constitute or imply its endorsement, recommendation, or favoring by the United States Government or any agency thereof. The views and opinions of authors expressed herein do not necessarily state or reflect those of the United States Government or any agency thereof. 
Reactor and Nuclear Systems Division

\title{
MODELING MOLTEN SALT REACTOR FISSION PRODUCT REMOVAL WITH SCALE
}

\author{
Pedro Jr. Vicente Valdez \\ Benjamin R. Betzler \\ William A. Wieselquist \\ Massimiliano Fratoni, UC Berkeley
}

February 2020

Prepared by

OAK RIDGE NATIONAL LABORATORY

Oak Ridge, TN 37831-6283

managed by

UT-Battelle, LLC

for the

US DEPARTMENT OF ENERGY

under contract DE-AC05-00OR22725 



\section{CONTENTS}

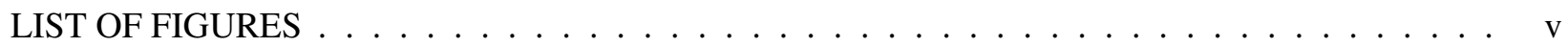

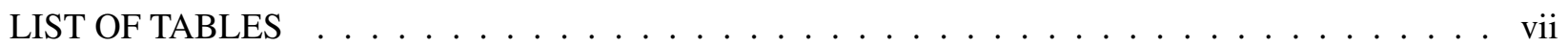

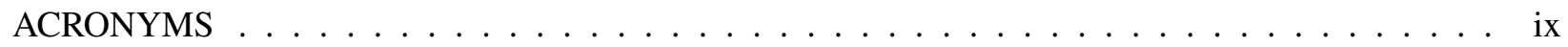

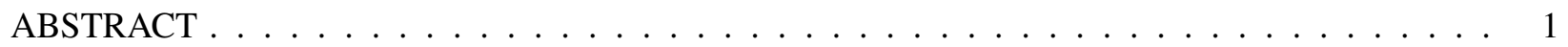

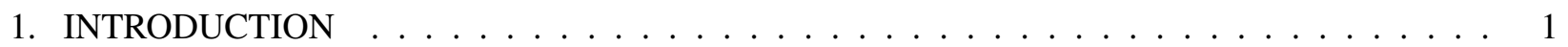

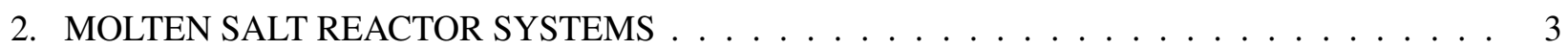

2.1 MOLTEN SALT REACTOR EXPERIMENT $\ldots \ldots \ldots \ldots \ldots \ldots$

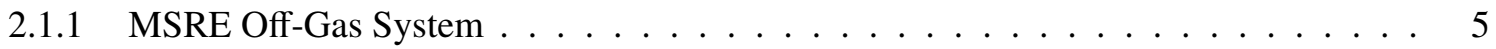

2.1 .2 The Krypton Experiment . . . . . . . . . . . . . . . . . . . . . 5

2.2 MOLTEN SALT BREEDER REACTOR AND MOLTEN SALT DEMONSTRATION

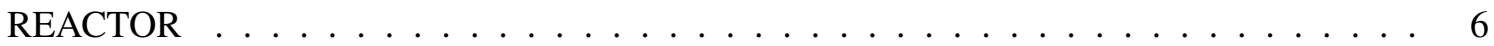

2.2.1 Molten Salt Breeder Reactor . . . . . . . . . . . . . . . . . . . . . 6

2.2.2 Molten Salt Demonstration Reactor . . . . . . . . . . . . . . . . . . 8

2.2 .3 MSDR and MSBR Off-Gas System . . . . . . . . . . . . . . . . . . . 9

3. REMOVAL RATES: THEORY AND CALCULATION . . . . . . . . . . . . . . . . . 12

3.1 FISSION PRODUCT SOURCES AND SINKS . . . . . . . . . . . . . . . . . 14

3.1 .1 Xenon Sources . . . . . . . . . . . . . . . . . . . . . . . 14

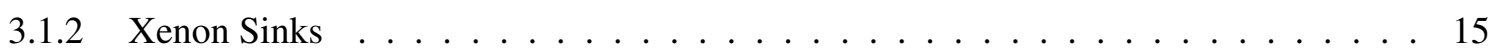

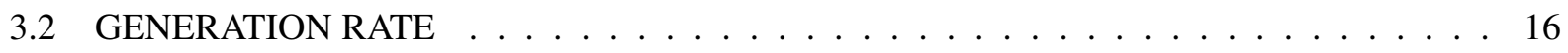

3.3 DECAY RATE IN PRIMARY FUEL LOOP . . . . . . . . . . . . . . . . . . 16

3.4 BURNUP RATE IN SALT . . . . . . . . . . . . . . . . . . . . . . 17

3.5 STRIPPING RATE AND GAS/LIQUID SEPARATOR EXTRACTION RATE $\ldots \ldots \ldots$

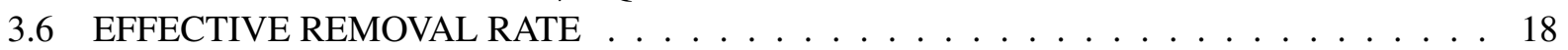

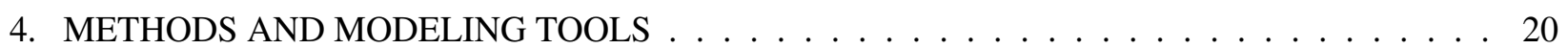

5. VALIDATING TRITON WITH THE MSRE AND APPLICATION TO THE MSBR AND

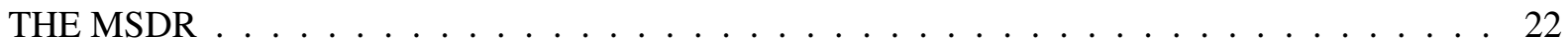

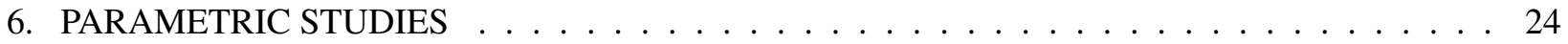

6.1 GAS/LIQUID SEPARATOR EFFICIENCY $\ldots \ldots \ldots \ldots \ldots \ldots \ldots$

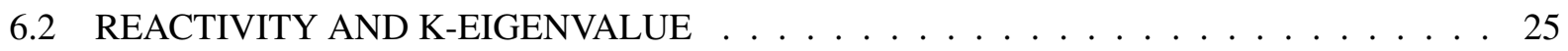

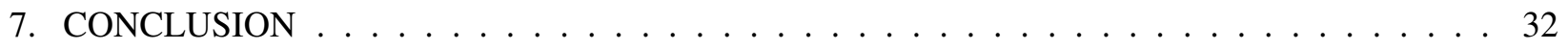

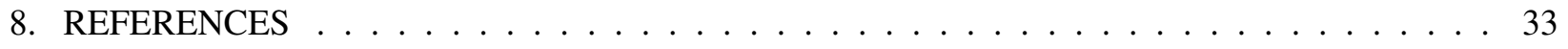

APPENDIX A. MODELING AND SIMULATION RESULTS FOR THE MSBR . . . . . . . . . A-1

APPENDIX B. MODELING AND SIMULATION RESULTS FOR THE MSDR . . . . . . . . . . . A-8 



\section{LIST OF FIGURES}

1 MSRE (a) primary fuel loop containing the reactor, pump, and heat exchanger, and (b) graphite slabs arranged to form fuel channels $[18] \ldots \ldots \ldots \ldots \ldots$

2 MSBR (a) graphite core zones, and (b) graphite pin dimensions. [19] . . . . . . . . . . . . 7

$3 \quad$ MSDR graphite cell [11] . . . . . . . . . . . . . . . . . . . . . . . . . . 9

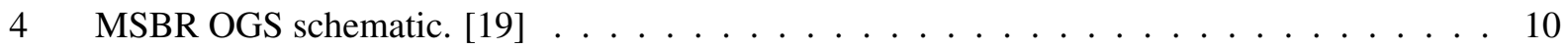

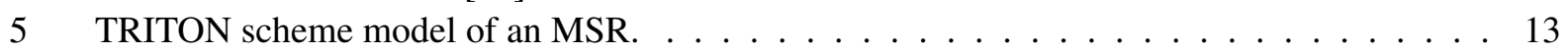

6 Unit cell model representations for the MSDR, MSBR, and MSRE (left to right) in SCALE. 20

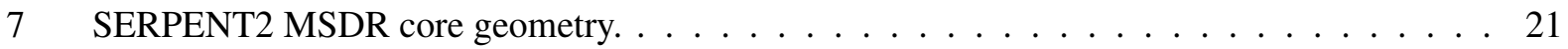

8 MSRE flux spectrum from SCALE and SERPENT2. . . . . . . . . . . . . . . . 22

$9 \quad$ MSRE $^{135}$ Xe poison fraction as a function of OGS efficiency. . . . . . . . . . . . . . . 24

10 MSRE ${ }^{135}$ Xe concentration (a) in the OGS and (b) in the PFL . . . . . . . . . . . . . . 28

11 MSRE $k_{\infty}$ as a function of OGS efficiency. . . . . . . . . . . . . . . . . 29

12 MSRE OGS efficiency impact on reactivity while in (a) operation and (b) turned on/off. . . . 30

13 MSR fuel lifetime enhancement as a function of OGS efficiency. . . . . . . . . . . . . 31

A-1 MSBR SCALE and SERPENT2 flux spectrum comparison. . . . . . . . . . . . . . A-3

A-2 MSBR poison fraction as a function of OGS efficiency. . . . . . . . . . . . . . A-4

A-3 $\mathrm{K}_{\text {inf }}$ as a function of OGS efficiency in the MSBR. . . . . . . . . . . . . . A-5

A-4 OGS efficiency impact on reactivity while in (a) operation and (b) turned on/off. . . . . . . . A-6

A-5 ${ }^{135}$ Xe concentration in (a) the OGS and (b) in the PFL. . . . . . . . . . . . . A-7

B-1 MSDR SCALE and SERPENT2 flux spectrum comparison. . . . . . . . . . . . . . B-3

B-2 MSDR poison fraction as a function of OGS efficiency. . . . . . . . . . . . . . . B-4

B-3 $\mathrm{K}_{\mathrm{inf}}$ as a function of OGS efficiency in the MSDR. . . . . . . . . . . . B-5

B-4 OGS efficiency impact on reactivity while in (a) operation and (b) turned on/off. . . . . . . . B-6

B-5 ${ }^{135}$ Xe concentration in (a) the OGS and (b) the PFL. . . . . . . . . . . . . . B-7 



\section{LIST OF TABLES}

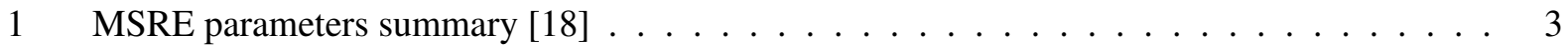

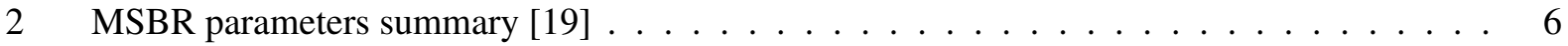

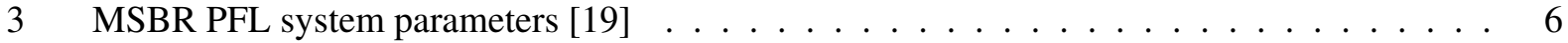

$4 \quad$ MSDR summary $[4] \ldots \ldots \ldots \ldots \ldots \ldots$

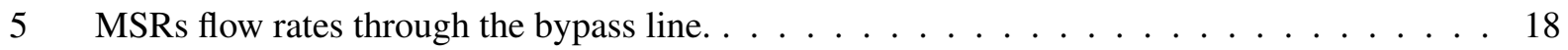

6 Removal constant calculation per reactor design . . . . . . . . . . . . . . . . . . . 19

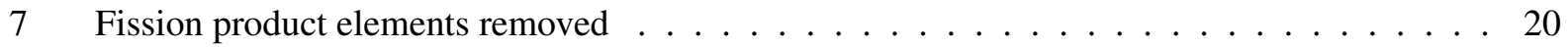

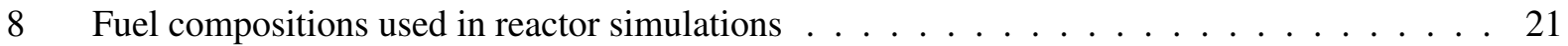

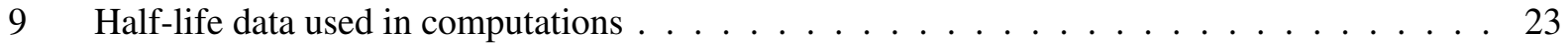

10 Fission yield data used in computations . . . . . . . . . . . . . . . . 23

11 MSRE ${ }^{135}$ Xe poison fraction at different OGS efficiencies . . . . . . . . . . . . . . . . 24

12 MSRE fuel lifetime improvement as a function of OGS efficiencies . . . . . . . . . . . . 26

13 MSBR fuel lifetime improvement as a function of OGS efficiencies . . . . . . . . . . . . 27

14 MSDR fuel lifetime improvement as a function of OGS efficiencies . . . . . . . . . . . 27

A-1 MSBR poison fraction at different OGS efficiencies . . . . . . . . . . . . A-4

B-1 MSDR poison fraction at different OGS efficiencies . . . . . . . . . . . . . B-4 



\section{ACRONYMS}

$\begin{array}{ll}\text { ANR } & \text { advanced nuclear reactor } \\ \text { ARE } & \text { Aircraft Reactor Experiment } \\ \text { FP } & \text { fission product } \\ \text { FS } & \text { fuel salt } \\ \text { HEU } & \text { highly enriched uranium } \\ \text { MSR } & \text { molten salt reactor } \\ \text { MSRE } & \text { Molten Salt Reactor Experiment } \\ \text { MSBR } & \text { Molten Salt Breeder Reactor } \\ \text { MSDR } & \text { Molten Salt Demonstration Reactor } \\ \text { LWR } & \text { light water reactor } \\ \text { LF-MSR } & \text { liquid-fuel molten salt reactor } \\ \text { PFL } & \text { primary fuel loop } \\ \text { PFL-S } & \text { primary fuel loop salt } \\ \text { ODE } & \text { ordinary differential equation } \\ \text { OGS } & \text { off-gas system } \\ \text { NRC } & \text { US Nuclear Regulatory Commission } \\ \text { ORNL } & \text { Oak Ridge National Laboratory }\end{array}$





\begin{abstract}
Liquid-fuel Molten Salt Reactors (MSRs) allow for continuous online fuel treatment and processing using a variety of subsystems. Among these subsystems, the off-gas system (OGS) continuously removes fission products from the primary fuel salt through a helium sparging process. Accurately modeling fission product behavior is paramount for the development of MSRs; while there are a variety of depletion modeling and simulation tools that allow for removal of material from a defined system, most of them work in a semicontinuous, batch-wise manner. The new tools implemented into TRITON, in the SCALE suite for reactor analysis and design, aim to address this issue by implementing truly continuous material feeds and removals. In addition, material accountancy is enhanced in these tools, which enable tracking of removed material in user-specified mixtures. These continuous depletion tools provide a way to model material transport throughout systems more efficiently and accurately. This report validates the new SCALE MSR modeling capabilities using data from the Molten Salt Reactor Experiment (MSRE). After a framework was established for deriving realistic removal rates based on design specifications, these rates were used by TRITON to continuously remove specific elements while performing burnup calculations. Results were compared to those obtained in MSRE, with a focus on the ${ }^{135}$ Xe poison fraction. After these capabilities were validated, the learned concepts and best practices were applied to model the Molten Salt Breeder Reactor (MSBR) and the Molten Salt Demonstration Reactor (MSDR) to study the effects of continuous fission product removal in fuel salt reactivity, as well as the lifetime effects.
\end{abstract}

\title{
1. INTRODUCTION
}

Among the recent initiatives for development of advanced reactor systems, liquid-fuel molten salt reactors (LF-MSRs) are gaining more interest, as detailed in the Third Way report on private investment in advanced nuclear reactors (ANRs) [7].Having the appropriate modeling and simulation tools is critical for development and licensing. Most tools have been developed for modeling light water reactors (LWRs) and are less appropriate for non-LWR reactors due to factors such as the phase and flow of the fuel. Therefore the appropriate tools and approaches for MSRs must be developed, with the ultimate goals of generating designs and licensing approved tools.

In an LF-MSR, the fuel is in liquid form, specifically, a molten salt such as $\mathrm{LiF}^{-\mathrm{BeF}_{2}}(\mathrm{FLiBe})$ salt containing dissolved fissile and fertile material. Fuel is circulated throughout the primary fuel loop (PFL) and undergoes irradiation when passing through the core region. Historically, operational experience with MSR technologies only existed during the Aircraft Reactor Experiment (ARE) and the 7.5 MWth Molten Salt Reactor Experiment (MSRE) [20]. Due to the phase of the fuel, use of these types of ANRs presents several opportunities, as well as challenges. Among these opportunities is reduced fuel pre-processing and the incorporation of subsystems for online fuel treatment that continuously treats and removes fission products and adjusts fissile concentration of the primary fuel loop salt (PFL-S). For example, in the MSRE, the off-gas system (OGS) was used to sparge gaseous fission products out of the PFL. Modeling liquid-phase fuels that continuously flow all throughout the PFL components presents a unique challenge. The appropriate tools will be selected based on the phenomena being studied. When simulating LF-MSRs, the change in isotopic composition in the PFL must be modeled while keeping track of materials flowing in and out of the system. This can be accomplished by defining mass transfer constants based on design specifications between subsystems. This is important not only from a reactor design perspective, but also from a safety standpoint, as radioactive elements have different pathways that take them out of core-an 
issue not present in conventional fixed fuel LWRs. Hence, it is important to track source terms throughout the system and subsystems to understand the life cycles of radioactive materials, their inventory, and other safety parameters that will ensure that system design is effective and that anticipated requirements are met regarding decay heat removal capacities, shielding of out-of-core components, appropriate holdup tank volumes, efficient charcoal bed systems, etc. Furthermore, it is important to understand the transport of some of these fission products from a neutron economy perspective. Many MSR concepts are envisioned to be breeder systems, and poisonous fission products such as ${ }^{135} \mathrm{Xe}$ have a significant negative impact on breeder potential. Rare earth elements are also known to impact the lifetime of the primary fuel loop salt [5]. Therefore, an appropriate neutronics and fuel cycle tool is needed to calculate changing MSR fuel composition and reactivity during operation.

Most of the current tools only have partial capabilities. Some model only equilibrium conditions after years of operation and do not account dynamically for the various phenomena acting on the PFL and the change in isotopic composition from startup to equilibrium and back to shutdown. These tools

$[13,16,12,10,9,22,2,17,1,3]$ are extended versions or sequences of common neutronic and depletion codes such as SERPENT [15], and ORIGEN. An external object-oriented Python script was written at Oak Ridge National Laboratory (ORNL) to manage (1) SCALE/TRITON calculations demonstrating the capability and functionality for MSR transport and (2) depletion calculations using semicontinuous feed and removals. This tool, ChemTriton, simulated not only equilibrium conditions, but also time-changing fuel cycle performance by modeling the change in isotopic composition of an irradiated mixture under changing operating parameters [5]. The outputs and inputs for subsequent calculations were automatically generated by ChemTriton given a set of input parameters. These capabilities have now been directly implemented into SCALE, bringing simplicity, faster run-times, accuracy, and truly continuous feed and removal tracking beyond the feed and removal ORIGEN depletion capabilities that were previously available. It is important to note that these capabilities focus primarily on simulating and studying the flow rate of radioactive material throughout the system and do not account for delayed neutron precursor drift due to its lesser impact on isotopic inventory.

In this work, three reactors were modeled, all of which use different fuel compositions in both the U/Pu and U/Th fuel cycles: MSRE, the Molten Salt Breeder Reactor (MSBR), and the Molten Salt Demonstration Reactor (MSDR) [18, 19, 4]. The effort began with four objectives: (1) set a framework for calculating useful removal rates from design specifications, (2) validate the new SCALE/TRITON capabilities by modeling gaseous fission product behaviour and calculating the ${ }^{135}$ Xe poison fraction in the MSRE and comparing results with those obtained by Kedl [14], (3) study the effect of the OGS efficiency in MSR operations and $k_{\text {eff }}$ (reactivity) in a parametric manner, and (4) develop a set of best practices that accurately model radioisotope transfer throughout user-defined mixtures. The approach was to study each system individually and derive an appropriate method for defining effective removal rates based on flows and mass transfer coefficients. Then, using these effective removal rates and a defined set of representative mixtures, burnup calculations were performed using TRITON's new feed/removal capabilities. The mixtures were defined in a manner that each represent different out-of-core systems like the OGS and the solid traps. Defining these mixtures allows source term inventory information to be tracked and gathered. The fuel salt mixture composition was used to calculate the poison fraction with SERPENT2, a continuous-energy Monte Carlo code. All calculations were run with SCALE 6.3b4 using the 252-group ENDF/B-VII.1 cross section library and SERPENT 2.1.31 [6, 15, 8]. 


\section{MOLTEN SALT REACTOR SYSTEMS}

This section briefly describes the three MSR systems simulated/modeled in this work: MSRE, MSBR, and MSDR. The MSBR and MSDR OGSs are described in the same subsection since they have many similarities. The fission product removal method is the same for all three reactors and will be described collectively.

\subsection{MOLTEN SALT REACTOR EXPERIMENT}

MSRE is a 7.5 MWth liquid-fueled graphite-moderated thermal spectrum MSR (Table 1). The fuel is a mixture of uranium, lithium, beryllium, and zirconium fluorides operating at approximately $922.03 \mathrm{~K}$. The lower enrichment fuel is 35\% enriched uranium while the highly enriched uranium (HEU) fuel is $92 \%$ enriched. While the MSRE includes a variety of subsystems, this work is mainly concerned with the PFL and the OGS.

Table 1. MSRE parameters summary [18]

\begin{tabular}{ccc}
\hline General & & \\
\hline Thermal power level & 7.5 & $\mathrm{MW}$ \\
Operating temperature & 922.03 & $\mathrm{~K}$ \\
Fuel salt flow rate & 0.07570824 & $\mathrm{~m}^{3} / \mathrm{s}$ \\
Xenon stripper flow rate & 0.00315451 & $\mathrm{~m}^{3} / \mathrm{s}$ \\
Salt flow along shaft to pump bowl & 0.000946353 & $\mathrm{~m}^{3} / \mathrm{s}$ \\
Fuel loop circuit time & 25.2 & $\mathrm{~s}$ \\
\hline Graphite & & \\
\hline Graphite volume & 1.95386 & $\mathrm{~m}^{3}$ \\
Density & $1.82-1.87$ & $\mathrm{~g} / \mathrm{cm}^{3}$ \\
\hline Fuel salt & \\
\hline Fuel salt volume & 1.996338 & $\mathrm{~m}^{3}$ \\
Melting temperature & 722.039 & $\mathrm{~K}$ \\
Density at 922K & 2.0824 & $\mathrm{~g} / \mathrm{cm}^{3}$ \\
\hline
\end{tabular}

The PFL contains several components, including the reactor, the primary fuel pump, and the heat exchanger (Figure 1a). The reactor core is mostly filled with graphite moderating slabs which are manufactured and arranged to form fuel channels through which the fuel salt flows (Figure 1b). The graphite is clad-less and is in direct and close contact with the fuel salt, so fission product migration can occur.

The molten salt acts as both the fuel and coolant. This means the salt is constantly entering and leaving the reactor core. First it flows out of the core through the piping until reaching the inlet of the primary fuel pump. A fraction of the salt flow is diverted and passes through the xenon stripper, which is located at the pump bowl. The xenon stripper is a toroidal shaped loop with small holes on the wall through which salt is sprayed into the helium atmosphere. At the pump bowl, a continuous amount of helium gas is introduced, and due to the chaotic nature of the xenon stripper sprayer, a fraction of helium gas is embedded into the salt and the PFL. Then the bubbled fuel salt moves towards the heat exchanger and back to the reactor core. Once the salt is back at the pump, the fission-product-saturated helium bubbles are extracted and transferred to the OGS. Details about this system, including the heat exchanger and the secondary fuel loop, can be found in Robertson's 1965 ORNL report [18]. 


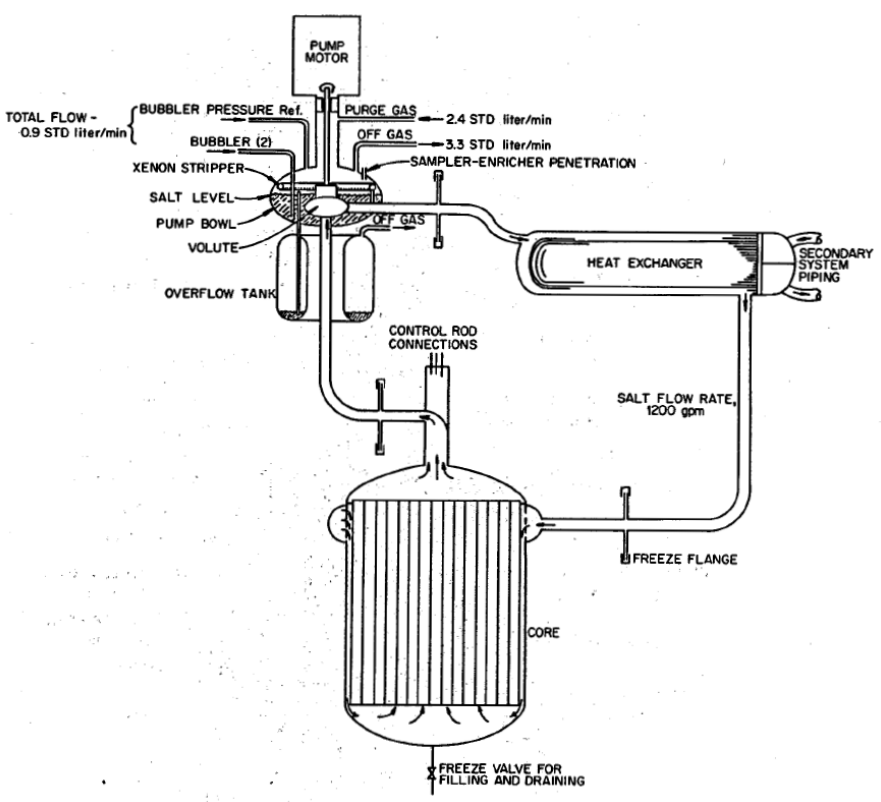

(a)

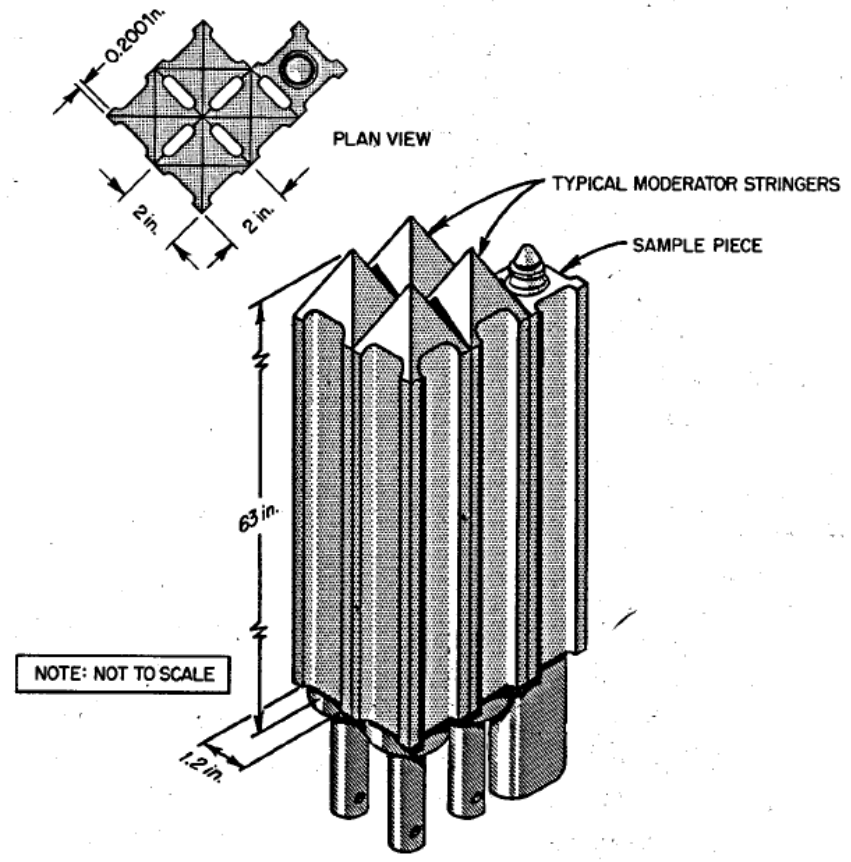

(b)

Figure 1. MSRE (a) primary fuel loop containing the reactor, pump, and heat exchanger, and (b) graphite slabs arranged to form fuel channels [18]. 


\subsubsection{MSRE Off-Gas System}

Since fissile concentration adjustments of the PFL salt are the main reactivity control mechanism, removal of fission products and their effect on reactivity must be carefully considered. One envisioned characteristic of future MSRs is the capability to breed fuel. The OGS is one essential auxiliary system designed in part to help achieve this characteristic in LF-MSRs. The OGS is connected to the PFL mainly through the primary fuel pump. In LF-MSRs, the OGS has several functions, including: (1) maintaining the salt free of oxygen, which merits the introduction of helium as a purging gas, (2) removing fission product using helium or argon as a carrier gas, and (3) adjusting the fissile concentration of the fuel salt.

The MSRE OGS is quite different from the OGSs in the MSBR and the MSDR. While the OGSs in all three reactors provide a constant introduction of clean helium, the locations of insertion into the PFLs and the methods vary. In the MSRE, the OGS inserts helium gas directly into the upper part of the pump bowl, creating a dense helium atmosphere. The fuel salt is then sprayed from the xenon stripper into the atmosphere. A fraction of the helium is embedded into the fuel salt in the form of bubbles. Gaseous fission products (e.g., ${ }^{135} \mathrm{Xe}$ ), migrate almost immediately to the interface or the interior of bubbles due to their high insolubility in molten salt. The bubble void fraction is an important parameter and will depend on the helium flow rate, the fuel salt flow rate, and the gas-removal rate. In the MSRE, no fraction of salt is extracted, and furthermore, the helium gas is not recycled. This results in the removal of gaseous substances with no recycling feeds with clean helium being introduced separately. This makes the MSRE system easier to model compared to the MSDR or MSBR, in which the cleanup efficiency of different subsystems in the OGS must be considered. The migration rates to bubbles and graphite and the gas stripping efficiency are the MSRE's only limiting factors for fission product removal.

\subsubsection{The Krypton Experiment}

Once a framework was established to derive effective removal rates, the new feed/removal and tracking capabilities of SCALE were validated. During the MSRE operations, an experiment was performed to study the behavior of fission products in the PFL and make preliminary calculations of mass transfer coefficients to graphite and to helium bubbles. The Krypton Experiment, which was performed in the pre-critical MSRE reactor, consisted of inserting specific, controlled amounts of ${ }^{85} \mathrm{Kr}$ into the PFL for specified periods of time. Soon after $120 \mathrm{Ci}$ of ${ }^{85} \mathrm{Kr}$ were inserted, the concentration of ${ }^{85} \mathrm{Kr}-\mathrm{a}$ semi-stable, low absorption cross section isotope-reached an equilibrium point. The krypton flow was then stopped while normal operations were maintained throughout the loop. During this experiment, the pump bowl was purged clean of krypton, the salt was stripped, and the graphite was leached. A radiation counter was placed on the off-gas line to monitor the amount of ${ }^{85} \mathrm{Kr}$ passing through the pump into the OGS. Using the gathered data, the competing mechanisms of migration of fission products to graphite versus migration to bubbles were studied, and mass transfer coefficients were derived. While this proved to be a difficult task involving some subjective interpretation and uncertainty, the experiment was performed on the actual MSRE molten salt loop. The coefficients extracted where adjusted and used to calculate the ${ }^{135} \mathrm{Xe}$ poison fraction. Details regarding the experiment and the results obtained can be found in the report by Kedl and Houtzeel [14]. The ${ }^{135}$ Xe poison fraction (Xe-PF) — which was calculated using the experimentally derived coefficients and a nominal stripping efficiency of $10 \%$-was $0.56 \%$. Preliminary measurements made on the critical reactor showed that xenon poisoning should be around $0.3-0.4 \%$. 


\subsection{MOLTEN SALT BREEDER REACTOR AND MOLTEN SALT DEMONSTRATION REACTOR}

\subsubsection{Molten Salt Breeder Reactor}

The Molten Salt Breeder Reactor (MSBR) design concept is a 1,000 MWe (2250 MWth) single-fluid MSR that operates in the Th-U fuel cycle (Table 2). The MSBR's fuel salt is similar to all reactors discussed herein, incorporating both fissile and fertile materials in the form of lithium, beryllium, thorium, and uranium fluorides (FLiBe salt), and it operates at approximately $978 \mathrm{~K}$. This system is designed as a breeder reactor with a breeding ratio of 1.06. Like previous concepts, long-term reactivity is primarily controlled by varying the amount of fissile concentration in the fuel salt, but it also incorporates a set of auxiliary control rods to control reactivity.

Table 2. MSBR parameters summary [19]

\begin{tabular}{ccc}
\hline General & & \\
\hline Thermal power level & 2,250 & $\mathrm{MW}$ \\
Thermal efficiency & 44.4 & $\%$ \\
Breeding ratio & 1.06 & - \\
Operating temperature & 978 & $\mathrm{~K}$ \\
\hline Graphite & & \\
\hline Density & 1.843 & $\mathrm{~g} / \mathrm{cm}^{3}$ \\
\hline Fuel salt & & \\
\hline Fuel salt in PFL & 48.7 & $\mathrm{~m}^{3}$ \\
Fuel salt in reactor & 30.4 & $\mathrm{~m}^{3}$ \\
Fuel salt in pump bowl & 5.2 & $\mathrm{~m}^{3}$ \\
Fuel salt in off-gas bypass loop & 0.3 & $\mathrm{~m}^{3}$ \\
Melting temperature & 722 & $\mathrm{~K}$ \\
Density at 978 K & 3.288 & $\mathrm{~g} / \mathrm{cm}^{3}$ \\
\hline
\end{tabular}

The MSBR reactor vessel is similar to that of the MSRE. It is a cylindrical container filled with graphite for neutron moderation, and to serve as a reflector. The salt flows upwards through the fuel channels formed from the shape and arrangement of the graphite slabs. The MSBR core fuel channels are cylindrical and vary in diameter, depending on their radial and axial locations in the core (Figures $2 \mathrm{a}$ and $2 \mathrm{~b}$ ). The MSBR's PFL contains four heat exchangers and four primary fuel pumps, all of which are placed in the reactor cell. All four pumps contain a bypass line in which a bubble generator and a gas/liquid separator are sequentially located. The bubble generator inserts helium bubbles directly into the PFL salt, while the gas/liquid separator separates both phases for extraction to the OGS. The MSBR also has a secondary salt cooling circulation system and a steam power system for the turbine-generator. More details on the system and its operation are available in Robertson's 1971 conceptual design study [19].

Table 3. MSBR PFL system parameters [19]

\begin{tabular}{ccc}
\hline Parameter & Value & Units \\
\hline Fuel salt mass flow rate & 1,665 & $\mathrm{~kg} / \mathrm{s}$ \\
Fuel salt density & $3,353.33$ & $\mathrm{~kg} / \mathrm{m}^{3}$ \\
Pipe radius & 0.0762 & $\mathrm{~m}$ \\
Pipe cross sectional area & 0.0182414 & $\mathrm{~m}^{2}$ \\
Velocity & 27.2193 & $\mathrm{~m} / \mathrm{s}$ \\
\hline
\end{tabular}




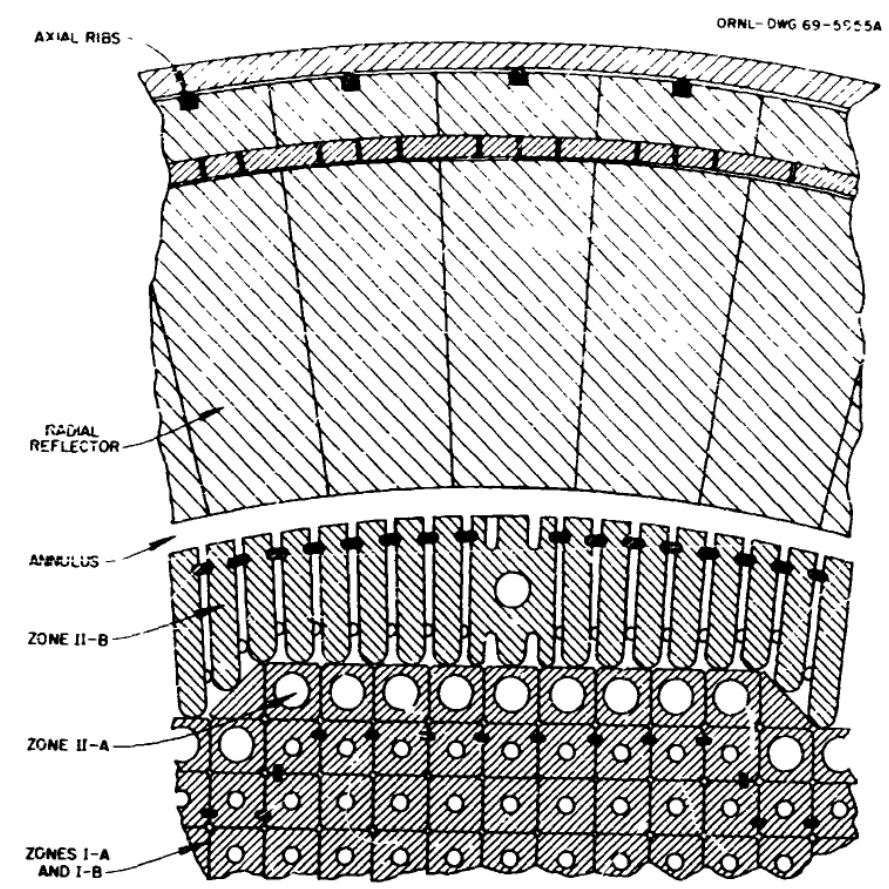

(a)
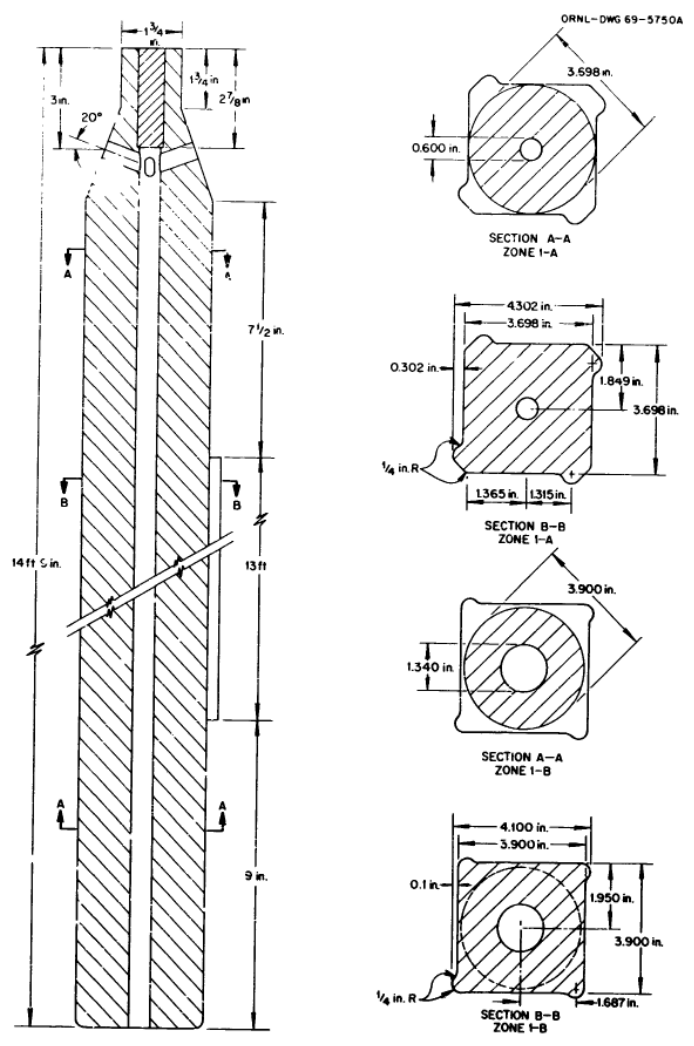

(b)

Figure 2. MSBR (a) graphite core zones, and (b) graphite pin dimensions. [19] 


\subsubsection{Molten Salt Demonstration Reactor}

The Molten Salt Demonstration Reactor (MSDR) is a 750 MWth fluoride-salt fueled thermal reactor concept (Table 4). It operates in the U/Pu fuel cycle with a 36.6\% conversion efficiency. The MSDR is the most recently developed concept of all three reactors mentioned in this work, leveraging many of the technological concepts of the MSRE and MSBR.

Table 4. MSDR summary [4]

\begin{tabular}{ccc}
\hline General & & \\
\hline Thermal power level & 750 & $M W$ \\
Electric power level & 350 & $M W$ \\
Thermal efficiency & 36.6 & $\%$ \\
Operating temperature & 898.15 & $\mathrm{~K}$ \\
\hline Graphite & & \\
\hline Density & 1.77666 & $\mathrm{~g} / \mathrm{cm}^{3}$ \\
Graphite mass in reactor & $662,436.4$ & $\mathrm{~kg}$ \\
Graphite volume in reactor & 372.8544 & $\mathrm{~m}^{3}$ \\
\hline Fuel salt & & \\
\hline Fuel salt mass in reactor & $100,802.38$ & $\mathrm{~kg}$ \\
Fuel salt volume in reactor & 30.0604 & $\mathrm{~m}$ \\
Fuel salt mass in PFL & $87,758.976$ & $\mathrm{~kg}$ \\
Fuel salt volume in PFL & $43.376,688$ & $\mathrm{~m}^{3}$ \\
Melting temperature & 722.039 & $\mathrm{~K}$ \\
Density at 898K & 3.35333 & $\mathrm{~g} / \mathrm{cm}^{3}$ \\
\hline
\end{tabular}

The entire OGS was modified from the MSBR to fit the MSDR, and the fuel processing plant was discarded. In addition to the OGS design, designs for the chemistry, materials, physics and fuel reprocessing, etc., were incorporated from the MSBR and the MSRE. The PFL is filled with U/Pu bearing molten FLiBe salt. It contains the reactor and three heat exchanger loops. Each of the three heat exchanger loops includes a sump-type centrifugal pump similar to those used in the MSBR. These pumps are used to remove volatile fission products by sparging the fuel salt with helium bubbles. As mentioned above, the pump incorporates a bypass line to purge fission gases from the salt. This line is used to extract a fraction of the fuel salt per pump from the pump outlet and back again into the inlet. A bubble generator and a gas/liquid separator are placed sequentially along the bypass line.

The reactor is a cylindrical vessel containing a graphite core with three main regions: the core region, the axial and radial reflectors, and a small inlet and outlet plenum. As in the MSRE and the MSBR, the graphite slabs are manufactured and assembled in a manner that permits fuel channels to form. A core graphite cell can be seen in Figure 3. In the radial and axial regions, a small gap is left among slabs to permit enough fuel salt to flow through and cool the reflectors. The reactor incorporates 6 auxiliary control rods, but the main reactivity control comes from adjusting the fissile concentration in the fuel salt.

In addition to the PFL, a primary coolant loop extracts heat from the primary fuel salt through all three heat exchangers. This heat is then transferred to a conventional steam system. Details on the primary coolant loop and the power cycle balance of the plant, along with information on the decay heat removal system, are described in Alexander et al. [4] and Betzler et al. [11]. 


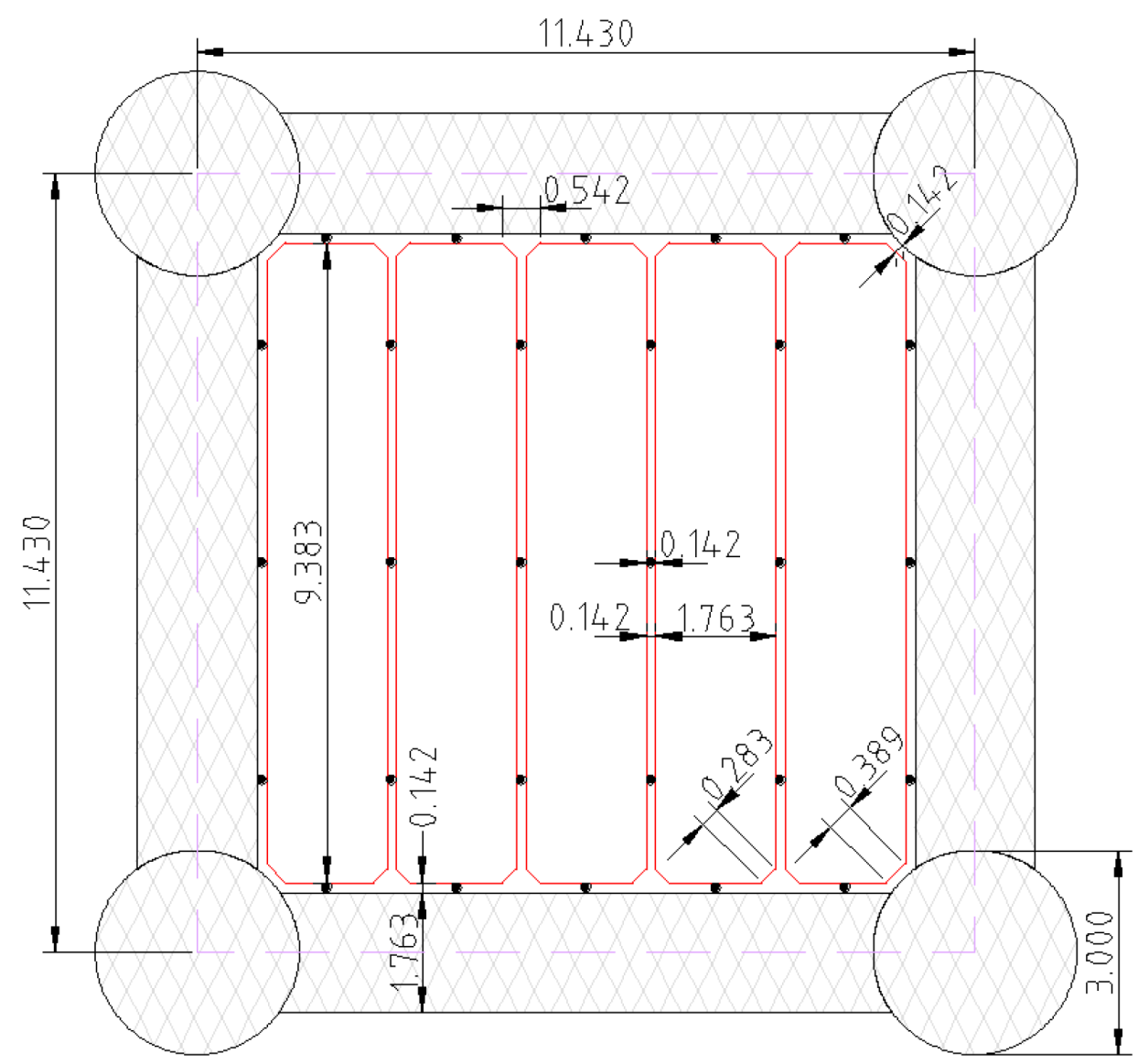

Figure 3. MSDR graphite cell [11]

\subsubsection{MSDR and MSBR Off-Gas System}

This section provides a more detailed description of the MSBR [19] and MSDR [4] OGSs. The primary purpose of the OGS is to remove undesirable contaminants from the PFLs, including gaseous and gas-borne fission products and fission product daughters. The OGS includes several components, as depicted in the OGS schematic (Figure 4). The OGS system removes contaminants by using helium or argon as a carrier gas for degassing/sparging the fuel salt.

The process is initiated by injecting helium gas into the PFL at the bubble generator, which is located along the primary fuel pump's bypass line. The bypass line diverts approximately $10 \%$ of the salt flow per pump. The bubble generator controls the bubble void fraction, which is defined as the fraction of helium bubbles in the entire PFL salt. The bypassed salt rejoins the main salt line, and bubbles begin dispersing all throughout the system. Gaseous fission products that are removed include xenon and krypton isotopes, tritium, oxygen from fluorine burnup and other noble gases and noble metal fission products. The solid fission products are removed via a solid trap, while the majority of the gaseous fission products-mainly xenon and krypton - strongly tend to migrate to other materials, including the graphite porous structure and the interfaces and interiors of the helium bubbles. In other words, gaseous fission products will form a true solution in salt, obeying the conventional laws of mass transfer (Henry's Law). After looping several 
times through the PFL, bubbles will head back to the pump through the bypass line, passing the bubble generator and progressing into the gas/liquid separator, where the fuel salt will be stripped from almost all gaseous fission products. The gas is redirected to the OGS in a volume ratio of 2:1 salt to gas.

The first subsystem in the OGS is the drain tank, which serves as a holdup tank for the entire primary fuel salt in case of shutdown or during an emergency procedure that requires draining the entire PFL. In either of these cases, the MSR PFL would drain via a freeze plug located at the bottom of the reactor core which leads to the drain tank located directly below. The drain tank is equipped with a NaK cooling system which removes heat via natural circulation to a water loop. The main function of the drain tank during normal operations is for residual heat removal and holdup volume for the first stage of fission product removal. This document only discusses the drain tank's role in the fission product removal process.

At the drain tank, the diverted gas/salt mixture is separated into a gas and salt phase through buoyant forces. The salt phase returns directly to the PFL through a pipe which can include several solid particle traps to remove some solid fission products. The gas is held up for several hours to allow the majority of ${ }^{135} \mathrm{Xe}$ to decay. The time needed varies according to the type of reactor system. For example, the holdup time in the MSBR specifications is 47 hours to allow 97\% of xenon isotopes to decay. In the MSDR, the necessary holdup time is approximately $4-6$ hours.

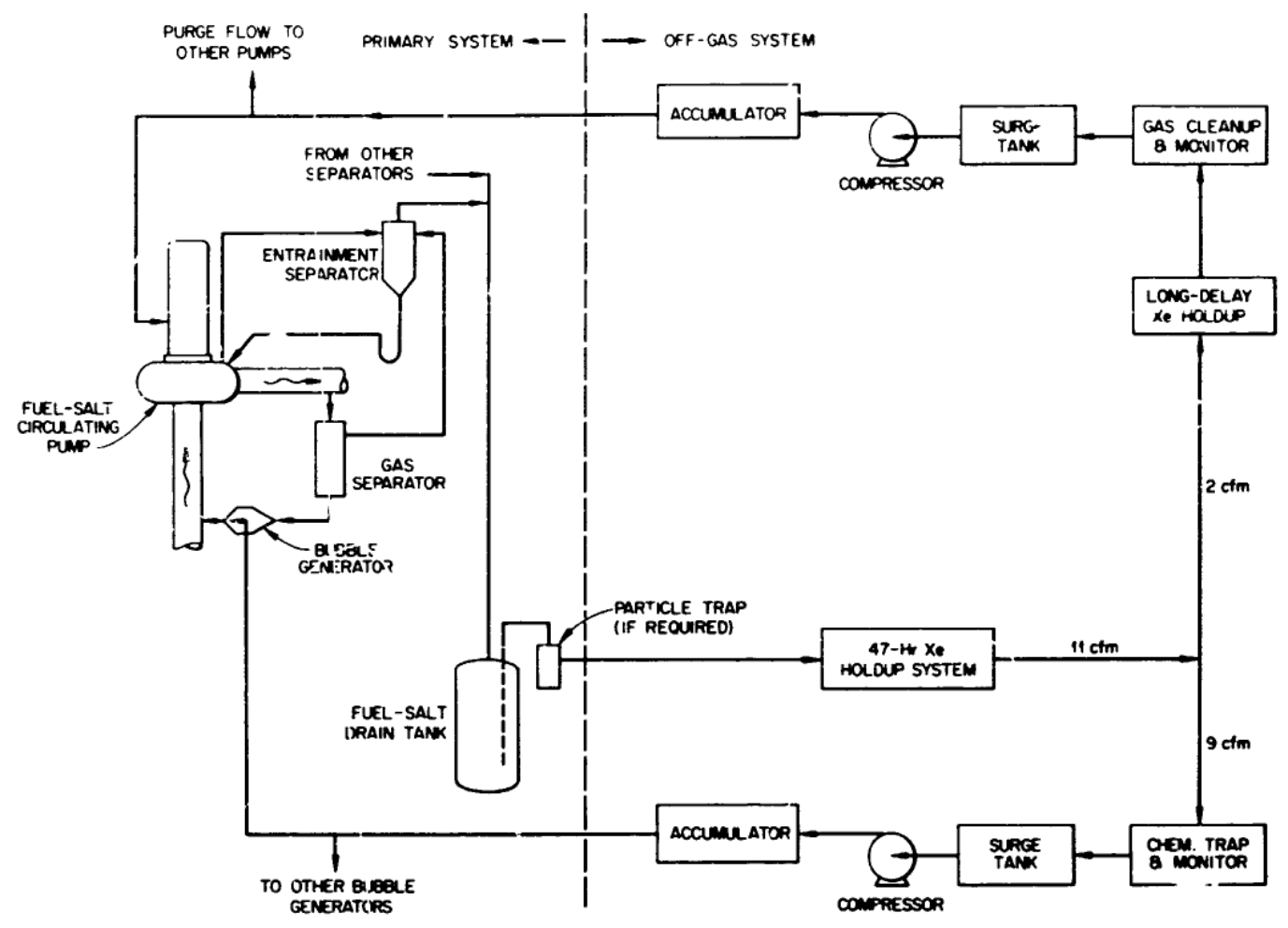

Figure 4. MSBR OGS schematic. [19]

After the holdup period has passed, the radioactive gas goes through one of two redundant particle traps to remove any solid products. At this point, the gas is assumed to be cleansed of nongaseous components (noble metals, salt mist, and nongaseous daughters of noble gases) and will consist mainly of krypton and xenon isotopes and tritium. The gas line coming out of the solid particle traps divides into two branches. Half of the gas goes directly back to the bubble generators, while the other half goes to the gas cleanup 
system. The gas cleanup system contains two redundant charcoal absorber beds which can be use alternatively if needed. The charcoal beds are designed to lower the amounts of ${ }^{85} \mathrm{Kr}$ and tritium to negligible levels so the gas can be stored and recycled. At the end of the $\approx 90$-day period, the cleansed gas heads to a storage tank, where it is metered back to the bubble generator and pumps for purging and sparging. The OGS is very involved in the normal operation of these MSRs and must therefore have a high degree of dependability and redundancy. Not only does the OGS have an impact on breeding potential, but it also affects the reactivity and lifetime of the fuel salt, as discussed in later sections. 


\section{REMOVAL RATES: THEORY AND CALCULATION}

This section defines removal rate as the rate at which a particular system or physical phenomenon removes elements/isotopes from the PFL to an unirradiated mixture. Similarly, feed rates are rates at which a particular system or phenomenon adds elements/isotopes to the PFL. Additionally, the effective removal rate is defined as the net rate by which elements/isotopes are added to and/or subtracted from the PFL. This work assumes that the fuel and fission products are homogeneously distributed throughout the PFL (the well-stirred pot model). For example, in the MSDR, the molten salt flow rate/velocity is high enough that the fuel makes approximately 1.16 loops per second.

To correctly set a framework for extracting the effective removal rate, the modeling capabilities must be understood so that usable values can be derived. ORIGEN solves a set of ordinary differential equations (ODEs) capturing nuclide generation, depletion, and decay, as shown in Eq. (1):

$$
\frac{d N_{i}}{d t}=\sum_{j \neq i}\left(l_{i j} \lambda_{j}+f_{i j} \sigma_{j} \phi\right) N_{j}(t)-\left(\lambda_{i}+\lambda_{i, r e m}+\sigma_{i} \phi\right) N_{i}(t)+S_{i}(t),
$$

where:

$N_{i}$ is the amount of nuclide $i$ (atoms),

$\lambda_{i}$ is the decay constant of nuclide $\mathrm{i}\left(\mathrm{s}^{-1}\right)$,

$\lambda_{i, \text { rem }}$ is the removal constant defining the continuous removal of nuclide $i\left(\mathrm{~s}^{-1}\right)$

$l_{i j}$ is the fractional yield of nuclide $i$ from decay of nuclide $j$,

$\sigma_{i}$ is the spectrum-averaged removal cross section for nuclide $i$ (barn),

$f_{i j}$ is the fractional yield of nuclide $i$ from neutron-induced removal of nuclide $j$,

$\phi$ is the angle- and energy-integrated, time-dependent neutron flux (neutrons $/ \mathrm{cm}^{2}-\mathrm{s}$ ), and

$S_{i}$ is the time-dependent source/feed term (atoms/s).

The ability to remove/feed and track different mixtures results in adding a term to the set of ODEs shown in Eq. (2), which—for unirradiated waste materials/mixtures—simply becomes Eq. (3).

$$
\begin{gathered}
\frac{d N_{i}}{d t}=\sum_{j \neq i}^{M}\left(l_{i j} \lambda_{j}+f_{i j} \sigma_{j} \phi\right) N_{j}(t)-\left(\lambda_{i}+\sum_{j}^{W} \lambda_{i, j k, r e m}+\sigma_{i} \phi\right) N_{i}(t)+\sum_{j}^{W} \lambda_{i, j k, r e c} N_{i}^{j}(t)+\sum_{j}^{Z} \lambda_{i, j k} N_{i}^{j}(t)+S_{i}(t) \\
\frac{d N_{i}}{d t}=\sum_{j}^{Z} \lambda_{i, j k, r e m} N_{i}^{j}(t)-\left(\lambda_{i}+\sum_{j}^{Z} \lambda_{i, k j, r e c}\right) N_{i}(t)
\end{gathered}
$$

where 
$\lambda_{i, j k, r e m}$ is the removal constant defining continuous removal of nuclide $i$ from irradiated material $j$ to waste stream $k$,

$\lambda_{i, j k, \text { rec }}$ is the recovery constant defining the continuous recovery of nuclide $i$ from waste stream $j$ back into irradiated material $k$, and

$N_{i}^{j}(t)$ is the concentration of nuclide $i$ in waste stream or irradiated material $j$.

An arbitrary number of mixtures can now be defined, along with their conditions (irradiated or decay only), and the feeds and removals between those mixtures. Due to the nature of the ODEs, these feeds and removals are defined as an additional decay constant $\left(\lambda_{i, j k, \text { rem }}\right) . \lambda_{i, j k, \text { rem }}$ must account for any removal mechanisms or phenomena acting on the irradiated material. This is similar to the standard preprocessing block in ORIGEN, except that by being able to define system-representative mixtures, information about the material that is fed or removed is no longer lost but is instead tracked, including data on inventory and composition. A detailed explanation of how these new capabilities were implemented can be found in Betzler [5].

In TRITON, the MSR system is modeled as a single molten salt reactor box (see Figure 5). This reactor box contains the salt in the primary fuel pumps, all primary fuel pipes, and all heat exchangers. The OGS will remove material from this mixture at a constant rate $\left(\lambda_{i, j k, \text { rem }}\right)$. Although feeding capabilities are available, they will not be used in this work. Instead, feeding phenomena will be taken into account by defining the effective removal rate. In MSRs, the material being constantly removed includes a variety of gaseous fission products and some solid fission products. In order to extract the removal rate that accurately captures this transport, the phenomena and systems acting on the fission products must be understood as they go from creation in the salt into the helium and throughout the cleanup systems.

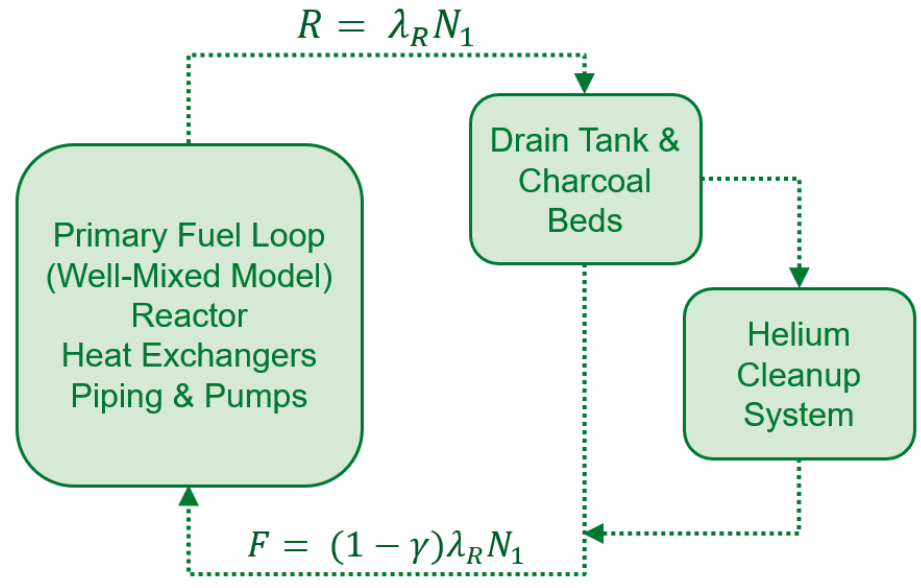

Figure 5. TRITON scheme model of an MSR.

The stripping efficiency is defined as the efficiency at which helium gas captures/absorbs gaseous fission products. In the MSRE Krypton Experiment, it was found that having the right graphite coating permeability and a bubble void fraction of $0.5 \%$ resulted in $95 \%$ of fission products (mainly xenon) being stripped by the helium bubbles. Increasing the bubble void fraction to $1.0 \%$ resulted in stripping efficiencies of $99 \%$ [14]. Based on these results, it is assumed that all fission products will be available for extraction from the PFL. 
For both the MSBR and the MSDR, approximately $10 \%$ of the fuel salt is bypassed, passing first through the bubble generator and then the gas/liquid separator. The separator efficiency limits the amount of fission products that can be extracted from the PFL. This is important since small differences in the separator efficiency will have a significant impact on the xenon poison fraction and consequently in reactivity. In the MSRE, the separator is only a gas extractor acting on the upper section of the pump bowl away from the fuel salt. For both the MSDR and the MSBR, a small fraction of salt is also sent to the drain tank. The removed gas/salt mixture will go through different cleansing processes. This will return a partially contaminated gas to the PFL, as well as clean helium (Figure 4). As mentioned above, any feed processes can be accounted for in the removal rates by including a correction factor.

\subsection{FISSION PRODUCT SOURCES AND SINKS}

Based on knowledge of the subsystems that compose the OGS, a framework can be established for deriving the removal rates from design specifications. This requires analysis of the fission product sources and potential sinks (including cleaning processes) throughout the system. For demonstration and simplicity, the following discussion focuses on ${ }^{135} \mathrm{Xe}$, but the process works the same way for other gaseous fission products, and with slight modifications, it also applies to solid fission products.

The number of a specific isotope $N_{i}$ in the salt is given by TRITON at any point in time during the transport/depletion calculations. The removal rate is simply defined as $R=\lambda_{i, j k, r e m} N_{i}$. All rates are given in units of number per unit time $\left(\mathrm{s}^{-1}\right)$. By conservation of mass, the generation rate of each isotope should equal the sum of all removal mechanisms. First, both the sources and sink terms for ${ }^{135} \mathrm{Xe}$ are defined:

$$
\text { Generation Rate }=\text { Decay Rate in Loop }+ \text { Burnup Rate in Loop }+ \text { Removal Rate }
$$

\subsubsection{Xenon Sources}

There are mainly two source terms for ${ }^{135} \mathrm{Xe}$ : fission and ${ }^{135} \mathrm{I}$ decay. These source terms are handled by TRITON in both the fuel salt and out-of-core mixtures. Given that the whole primary fuel salt is being burned inside the simulation as a single salt volume (i.e., the reactor box model), it is important to address the fact that only the fraction of the salt passing through the core actually gets irradiated. This issue can be addressed by implementing a correction factor in one of two ways. The reaction rate is a function of flux $(\phi)$ and macroscopic cross section $(\Sigma)$. The latter is a function of number density $(N)$ and microscopic cross section $(\sigma)$. The generation of ${ }^{135} \mathrm{Xe}$ is given by the reaction rate multiplied by the fission yield $(\nabla)$. Since the model would overestimate generation rates, a correction factor $(\gamma)$ can be introduced which can take the form of a number density correction constant as shown in Eq. (5). Alternatively, in TRITON, this must be represented as an additional sink which would remove products that should not have been generated in the first place, as shown in Eq. (6). These products would be removed at a constant rate. The MSBR and MSDR fuel salt flow rates are high enough that their cycle loop times are $>1$. It can be assumed that every atom/volume passes through the core at least once per second. This translates to lowering the specific power since we now account for more salt being irradiated than that in the core. 


$$
\begin{gathered}
\text { Reaction Rate }=\gamma * \nabla * \Sigma * \phi \\
\lambda_{\text {correction }}=(1-\gamma) \\
\text { Correction Removal }=\lambda_{\text {correction }} * N_{X}
\end{gathered}
$$

- Xenon from Fission. The ${ }^{135} \mathrm{Xe}$ production rate from fission is given by its independent fission yield, which is approximately 0.00178 for thermal neutrons in ${ }^{235} \mathrm{U}$ [8]. This is time dependent based on fissile material inventory.

- Xenon from Iodine Decay. The greatest source of ${ }^{135} \mathrm{Xe}$ is iodine decay. The yield for ${ }^{135} \mathrm{I}$ per fission is approximately 0.0293 , which decays with a half life of $6.58 \mathrm{~h}$. Additionally, ${ }^{135} \mathrm{Te}$, which has a fission yield of 0.0322 , will also contribute to the ${ }^{135} \mathrm{Xe}$ concentration by decaying into ${ }^{135} \mathrm{I}$ with a half life of $\approx 19 \mathrm{~s}$.

\subsubsection{Xenon Sinks}

For all reactors, a well-mixed pot reactor model is assumed, meaning that fission products are considered to be distributed homogeneously throughout the system. Only isotopes with half lives shorter than $1.16 \mathrm{~s}$ (or $25 \mathrm{~s}$ for the MSRE) should receive more detailed consideration when calculating isotope-specific removal constants.

- Xenon Burnup and Decay. A fraction of xenon will be continuously removed (i.e., burned) due to its high absorption cross section (,$\gamma$ reaction). Since a well-mixed-pot model is being assumed, in TRITON, burnup is corrected for by lowering the specific power transforming the model from a core phenomenon into a loop phenomenon. Xenon will decay everywhere throughout the PFL. This should be be considered when studying neutron precursor drift and performing safety analysis, but the focus in this work is on material transport from the PFL to out-of-core systems. This ${ }^{135} \mathrm{Xe}$ sink is simply the decay constant $\left(\lambda_{\text {Decay }}\right)$.

- Xenon Stripper Efficiency. The stripping efficiency, defined as the percentage of fission products migrated from the salt to the bubbles in the primary fuel loop, depends mostly in two transfer phenomena:

- Xenon Migration to Graphite. The graphite slabs in the core act as a concentrating point for insoluble (and some soluble) fission products, mainly xenons and kryptons. The rate of migration will be a function of the mass transfer coefficient from salt to graphite, which is a strong function of coating permeability and density. The fraction of fission products absorbed in graphite will not be available for removal unless enough fission products are removed from the PFL to cause a shift in equilibrium. If no fission products are being generated but the OGS keeps operating by inserting bubbles and extracting the gaseous phase, then any trapped fission products will eventually be leached from graphite.

- Xenon Migration to Bubbles. Gaseous fission products like ${ }^{135} \mathrm{Xe}$ are highly insoluble in molten salt and will show a strong tendency to migrate to the interface and interiors of the bubbles. The migration rate depends on the mass transfer coefficient from salt to bubbles, which in turn depends on bubble size, surface area, and fission product concentration at the 
interface. Relative low bubble void fractions are known to be capable of achieving high fission product capture. If high enough, graphite will be leached continuously, preventing fission products from being retained in the core. Steady-state calculations assume that the flux to bubbles is equivalent to the stripping rate, which will depend on the stripping efficiency.

Migration to graphite and migration to bubbles are the most important mechanisms for achieving a low poison fraction core. This work assumes that the bubble void fraction in all three reactor concepts is high enough that all gaseous fission products generated will immediately migrate to the interior of the bubbles and will therefore immediately leach graphite. The stripping efficiency nominal value, $S$, will therefore be $99.99 \%$.

The following section describes each source and sink mathematically, and isotopic removal rates are calculated. Xenon-135 and the MSDR are used as the example throughout the following subsections.

\subsection{GENERATION RATE}

The MSDR is a $750 \mathrm{MWth}$ thermal reactor. The fission rate is simply given by the thermal power and the energy released per fission. The xenon generation rate is the fission rate multiplied by the fission yield $(\nabla)$.

$$
\begin{gathered}
\text { Fission Rate }=(750 \mathrm{MWth})\left(6.242 \cdot 10^{18} \frac{\mathrm{MeV}}{\mathrm{MJ}}\right)\left(\frac{1}{200 \mathrm{MeV} / \text { fission }}\right) \\
\text { Fission Rate }=2.34075 \cdot 10^{19} \text { fissions } / \mathrm{second} \\
{ }^{135} \mathrm{Xe} \text { Gen. Rate }=\nabla \cdot \text { Fission Rate } \\
{ }^{135} \mathrm{Xe} \text { Gen. Rate }=(0.06328 \mathrm{Xe} / \text { fission }) \cdot\left(2.34075 \cdot 10^{19} \mathrm{fission} / \mathrm{s}\right) \\
{ }^{135} \mathrm{Xe} \text { Gen. Rate }=1.4812266 \cdot 10^{18} \mathrm{Xe} \text { atoms } / \mathrm{sec}
\end{gathered}
$$

\subsection{DECAY RATE IN PRIMARY FUEL LOOP}

The decay rate $(D)$ in the primary fuel loop is a function of the decay constant, the volume of salt in the primary fuel loop $\left(V_{S}\right)$, and the concentration of ${ }^{135} \mathrm{Xe}$ in the salt $\left(C_{S}^{X e}\right)$, which is given in units of $m^{-3}$.

$$
\begin{gathered}
D=\frac{\ln (2)}{t_{\frac{1}{2}}} \cdot V_{S} \cdot C_{S}^{X e} \\
D=\lambda_{\text {decay }} \cdot V_{S} \cdot C_{S}^{X e} \\
D=\frac{\ln (2)}{32904 \mathrm{~s}} \cdot V_{S} \cdot C_{S}^{X e} \\
D=2.106574 \cdot 10^{-5} / s \cdot V_{S} \cdot C_{S}^{X e}
\end{gathered}
$$

This can be simplified further to become 


$$
\begin{gathered}
D=\lambda_{\text {decay }} \cdot N_{\text {total }} \\
D=2.106574 \cdot 10^{-5} / \mathrm{s} \cdot N_{\text {total }} \\
\lambda_{\text {decay }}=2.106574 \cdot 10^{-5} / \mathrm{s},
\end{gathered}
$$

since

$$
C_{S}^{X e}=\frac{N_{\text {total }}}{V_{S}}
$$

The half life of ${ }^{135} \mathrm{Xe}$ is well above the fuel loop cycle time. While this important for safety and activation analysis, the decay rate in the PFL can be considered negligible for long equilibrium burnup calculations due to the well-mixed model approximation.

\subsection{BURNUP RATE IN SALT}

The burnup rate and depletion calculations are performed by TRITON. This work uses NEWT, a 2D-deterministic transport code, coupled with ORIGEN. The specific power was lowered assuming a fast enough cycle loop time. The fuel salt volume used to calculate the specific power is that of the entire loop, while the reactor power is kept constant, as shown in Eq. (21).

$$
\text { Burnup Rate in Salt }[\text { MW/MTHM }]=\frac{\text { Thermal Power }}{\text { Heavy Metal Density } * \text { PFL Salt Volume }}
$$

\subsection{STRIPPING RATE AND GAS/LIQUID SEPARATOR EXTRACTION RATE}

Since all fission products in the PFL are available for extraction, the next limiting factor becomes the gas/liquid separator system. The efficiency depends purely on the equipment used. In the MSRE case, there is no separator, so the gas/liquid separator efficiency is $100 \%$, and the nominal value for stripping efficiency used was $10 \%$, although preliminary reports indicate that the value is actually upwards of $50 \%$. For the MSBR and MSDR, the gas/liquid separator acts on the bypassed line salt. Flow rates through the bypass line and other relevant information can be seen in Table 5.

The extraction rate is expressed as a function of the salt flow rate through the gas/liquid separator $\left(Q_{s p}\right)$, the stripping efficiency $(S)$, the gas/liquid separator's efficiency $(G)$, the number of pump bypass lines $(L)$, and the concentration of ${ }^{135} \mathrm{Xe}$ in the salt. 
Table 5. MSRs flow rates through the bypass line.

\begin{tabular}{|c|c|c|c|c|}
\hline & MSDR [4] & MSRE $^{a}[18]$ & MSBR [19] & Units \\
\hline Bypass flow rate & 0.054749602 & 0.00410086 & 0.099982744 & $\mathrm{~m}^{3} / \mathrm{s}$ \\
\hline Salt fraction extracted to drain tank & 1 & - & 1 & $\%$ \\
\hline Substance removal efficiency ${ }^{b}$ & 100 & 100 & 100 & $\%$ \\
\hline Substances separated & G-FP/S-FP & G-FP & G-FP/S-FP & - \\
\hline
\end{tabular}

${ }^{(a)}$ The flow rate represents that calculated at the xenon stripper toroidal loop. The flow was never directly measured. Estimates indicate a flow of approximately $0.003153 \mathrm{~m}^{3} / \mathrm{s}$ (with an additional $0.000946353 \mathrm{~m}^{3} / \mathrm{s}$ flow behind the impeller).

${ }^{(b)}$ This applies to long-lived isotopes. Short-lived isotopes are addressed in the text of the document.

$$
\begin{aligned}
& \text { Extraction Rate }=Q_{s p} \cdot S \cdot G \cdot L \cdot C_{s}^{X} \\
& \text { Extraction Rate }=Q_{s p} \cdot S \cdot G \cdot L \cdot \frac{N_{\text {total }}}{V_{S}} \\
& \text { Extraction Rate }=0.0547496 \frac{\mathrm{m}^{3}}{\mathrm{~s}} \cdot 99 \% \cdot 10 \% \cdot 3 \cdot \frac{N_{\text {total }}}{41.31242 \mathrm{~m}^{3}} \\
& \text { Extraction Rate }=0.000393601 / s \cdot N_{\text {total }} \\
& \lambda_{\text {Extraction }}=0.000393601 / \mathrm{s}
\end{aligned}
$$

In the MSBR and MSDR systems, not only gas is extracted, but also a small fraction of molten salt. It is assumed that any gaseous fission products remaining in the small fraction of diverted salt will be stripped. In both of these reactors, the gas is treated for radioactive element removal. The OGS is assumed to be efficient enough to remove all fission products except for long lived isotopes. Long lived isotopes are only completely removed in the portion of the gas that heads to the cleanup system. Overall, the OGS in the MSDR is said to have an efficiency of 50\%, and the OGS in the MSBR is said to have an efficiency of $70 \%$ (based on the branching ratios). For the MSRE, all the bypassed products do not return to the PFL, so the OGS will be $100 \%$ efficient in removing fission products.

\subsection{EFFECTIVE REMOVAL RATE}

All items needed to calculate the effective removal rate for each system have now been defined.

Effective Removal Rate $\left(\lambda_{e f f}\right)=$ Decay Rate in Loop + Extraction Rate + Correction Factor

The correction factor is optional. If the specific power is lowered, then this factor should not be included. The effective removal rate can be represented either in terms of concentration: 


$$
\begin{gathered}
\lambda_{e f f} \cdot C_{S}^{X e}=\left[8.702767 \cdot 10^{-4} \frac{m^{3}}{s} \cdot C_{S}^{X e}\right]+\left[0.005475 \frac{m^{3}}{s} \cdot C_{s}^{X} \cdot \# \text { of Loops }\right] \\
\lambda_{e f f} \cdot C_{S}^{X e}=0.017295156 \frac{\mathrm{m}^{3}}{s} \cdot C_{s}^{X e},
\end{gathered}
$$

or, more appropriately for TRITON, in terms of numbers:

$$
\begin{gathered}
\lambda_{e f f} \cdot N_{X e}=\left[2.1065742 \cdot 10^{-5} / s \cdot N_{X e}\right]+\left[1.32526 * 10^{-4} / s \cdot N_{X e} \cdot \# \text { of Loops }\right] \\
\lambda_{e f f} \cdot N_{X e}=0.00041864 / s \cdot N_{X e} \\
\lambda_{e f f}=0.00041864 / s
\end{gathered}
$$

The calculation remains the same for all fission products. The only terms that may vary are the decay rate in the loop and the efficiency of the OGS in isotope-dependent cases. Removal rates using nominal values for the three MSRs are given in Table 6.

Table 6. Removal constant calculation per reactor design

\begin{tabular}{ccccc}
\hline & MSDR & MSRE & MSBR & Units \\
\hline Volume (PFL) & 41.312 & 1.996 & 40.096 & $\mathrm{~m}^{3}$ \\
Density & 3379.02 & 2146.47 & 3283.90 & $\mathrm{~kg} / \mathrm{m}^{3}$ \\
Number of PFLs & 3 & 1 & 4 & - \\
Gas separator efficiency & 0.1 & 0.1 & 0.1 & $\%$ \\
Removal constant & $3.97577 \times 10^{-4}$ & $2.05419 \times 10^{-4}$ & $9.97417 \times 10^{-4}$ & $\mathrm{~s}^{-1}$ \\
\hline
\end{tabular}




\section{METHODS AND MODELING TOOLS}

ORIGEN solves a set of ODEs, where the fluxes and cross sections are provided by a transport calculation. This work used the NEWT code, a 2D multigroup discrete-ordinates radiation transport computer code, coupled with ORIGEN. The coupling is handled by the TRITON sequence.

The unit cell approach was used, which saves calculation time while providing an accurate spectrum within the fuel for depletion calculations [5]. For all unit cells, a $30 \times 30$ mesh was defined, and reflective boundary conditions were used. Models for three different MSR designs were created in SCALE-6.3.4b and SERPENT2-MSDR, MSBR, MSRE (Figure 6). For the MSDR, the full-core model was developed in SERPENT2 to validate the unit cell approximation (Figure 7). The MSBR and MSRE were validated in a previous report [21]. The same 252 energy group was used in both SCALE and SERPENT2. All reactors have thermal spectra, but they use different fuel compositions (Table 8). The initial loading of fuel in all three reactors' unit cells results in a supercritical configuration. For validation purposes, fuel was only burned, and no feeds where defined.
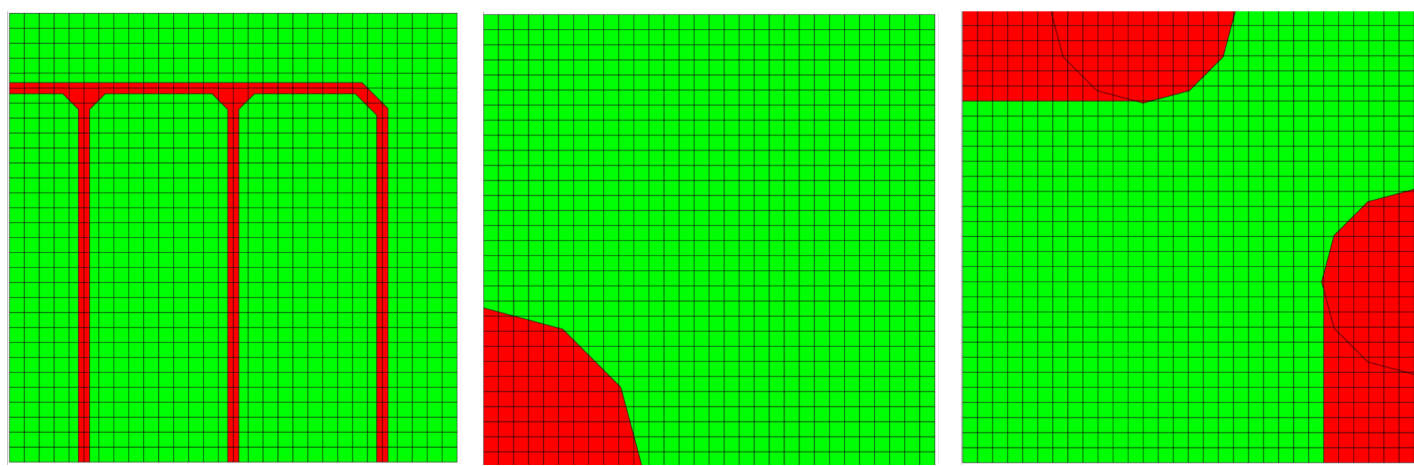

Figure 6. Unit cell model representations for the MSDR, MSBR, and MSRE (left to right) in SCALE.

In the TRITON input, three mixtures where defined for all cases.

- Mixture 1 contains the reactor box materials. Initially, this consists on the fresh fuel salt mixture. This mixture is set to be constantly depleted (irradiated), and if it is defined, then it is fed with fissile and fertile material.

- Mixture 2 represents the OGS. In TRITON, the derived removal constants are set to feed material from Mixture 1 to Mixture 2. The elements specified for removal in this work are mostly gaseous fission products.

- Mixture 3 includes solid fission products, including noble metals, which are fed from Mixture 1 to Mixture 3.

Table 7. Fission product elements removed

\begin{tabular}{cc}
\hline Processing group & Elements \\
\hline Gaseous fission products & $\mathrm{Xe}, \mathrm{Kr}, \mathrm{Ar}, \mathrm{He}, \mathrm{N}, \mathrm{O}$ \\
Noble metals & $\mathrm{Se}, \mathrm{Nb}, \mathrm{Mo}, \mathrm{Tc}, \mathrm{Ru}, \mathrm{Rh}, \mathrm{Pd}, \mathrm{Ag}, \mathrm{Sb}, \mathrm{Te}$ \\
\hline
\end{tabular}




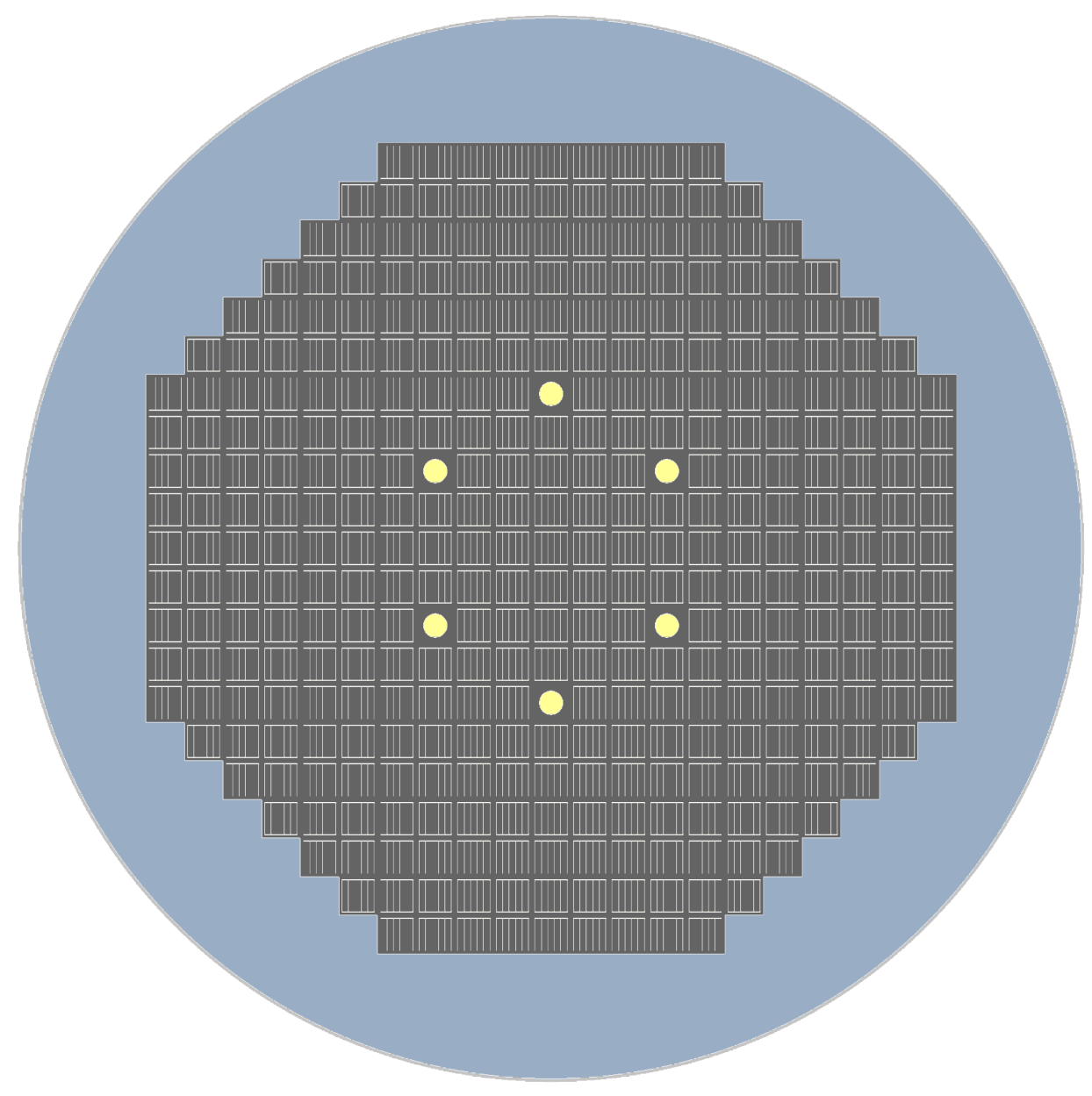

Figure 7. SERPENT2 MSDR core geometry.

Table 8. Fuel compositions used in reactor simulations

\begin{tabular}{ccccc}
\hline Composition & MSRE 35\% & MSRE HEU & MSBR & MSDR \\
\hline mole \% & 65.0 & 66.8 & 71.7 & 67.0 \\
$\mathrm{LiF}$ & 29.1 & 29.0 & 16.0 & 23.0 \\
$\mathrm{BeF}_{2}$ & 5.0 & 4.0 & 0.0 & 0.0 \\
$\mathrm{ZrF}_{4}$ & 0.0 & 0.0 & 12.0 & 10.0 \\
$\mathrm{ThF}_{4}$ & 0.9 & 0.2 & 3.0 & 0.0 \\
$\mathrm{UF}_{4}$ & 35.0 & 92.0 & 99.9 & 93.0 \\
Enrichment & 32.16 & 139.06 & 38.40 & 6.19 \\
Specific power $(\mathrm{MW} / \mathrm{MTHM})$ & 2.14647 & 2.0824 & 3.288 & 4.710 \\
Density $\left(\mathrm{g} / \mathrm{cm}^{3}\right)$ & & & & \\
\hline
\end{tabular}




\section{VALIDATING TRITON WITH THE MSRE AND APPLICATION TO THE MSBR AND THE MSDR}

During the operation of the MSRE, calculations performed on the pre-critical system hinted at a poison fraction ranging from $0.3-0.4 \%$. Computational models created to calculate the poison fraction in the system using experimental data resulted in a poison fraction of $0.56 \%$, which is referred to herein as the target poison fraction [14]. The removal constant used in the present calculations for the MSRE can be found in Table 6. This removal constant is the pre-decay removal constant. For each isotope, the respective decay constant must be summed to obtain the effective removal constant. For example, for ${ }^{135} \mathrm{Xe}$ the effective removal constant is as follows:

$$
\begin{gathered}
\lambda_{\text {pre-eff }}=0.000205419 / \mathrm{s}+\lambda_{\text {decay }} \\
\lambda_{\text {eff }}=0.000226336 / \mathrm{s}
\end{gathered}
$$

Recall that the effective removal constants are obtained using a 10\% stripping efficiency. SCALE inputs were prepared using the fuel composition in Table 8 and a unit cell geometry. The fuel was burned for 730 days in accordance with calculations performed by Kedl [14]. The flux spectrum of the MSRE unit cell in both SCALE and SERPENT can be seen in Figure 8. The spectra for the MSBR and MSDR are found in Figure A-1 of Appendix A and Figure B-1 of Appendix B, respectively.

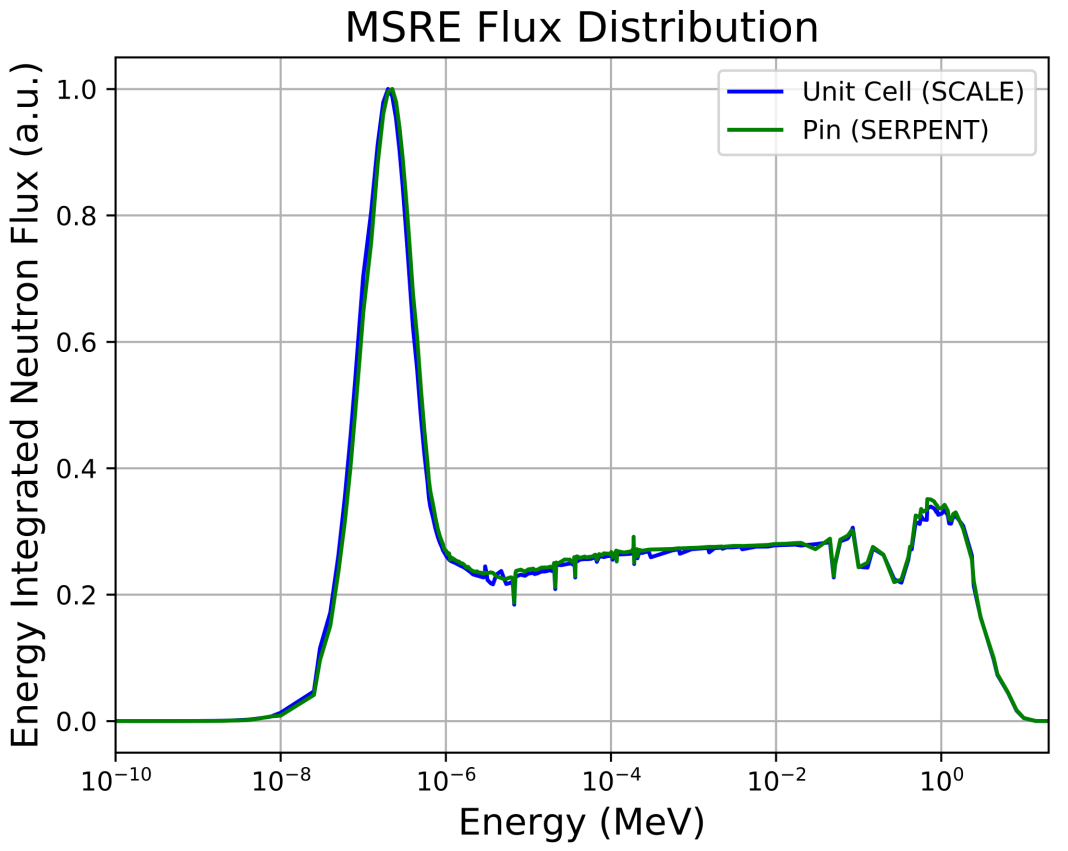

Figure 8. MSRE flux spectrum from SCALE and SERPENT2.

After performing the burnup calculations in TRITON using the new continuous removing and tracking capabilities, the final composition was used as the fuel composition input in SERPENT2. Detector response functions for ${ }^{135} \mathrm{Xe}$ and ${ }^{235} \mathrm{U}$ were defined to calculate the poison fraction ${ }^{233} \mathrm{U}$ in the MSDR 
case). The poison fraction is defined as the ratio of neutrons absorbed in ${ }^{135} \mathrm{Xe}$ to the neutrons absorbed in fissile isotope-in this case, ${ }^{235} \mathrm{U}$, as shown in Eq. (35).

$$
{ }^{135} \text { Xe poison fraction }=\frac{\phi \Sigma_{a_{t} o t}^{X e-135}}{\phi \Sigma_{a_{t} o t}^{U-235}}
$$

It was found that at $10 \%$ off-gas efficiency, the obtained poison fraction was 0.00602 (approximately $7 \%$ off the target poison fraction). While $7 \%$ is a considerable deviation, a variety of factors justify this result. In the calculation performed by Kedl, several fundamental parameters were outdated. For instance, the decay constants employed for several key isotopes were different, therefore introducing uncertainties up to $1.5 \%$ (Table 9). This is considerable, especially since it has a direct effect on the amount of ${ }^{135} \mathrm{Xe}$ available at a specific time. Additionally, different fission yields where used on their calculations, therefore adding to the overall error (Table 10).

Table 9. Half-life data used in computations

\begin{tabular}{|c|c|c|c|}
\hline \multirow{2}{*}{ Isotope } & \multicolumn{2}{|c|}{ Half- life (hours) $t_{1 / 2}$} & \multirow{2}{*}{ Deviation } \\
\hline & Kedl [14] & Present & \\
\hline${ }^{135} \mathrm{I}$ & 6.68 & 6.58 & 0.0151976 \\
\hline${ }^{135} \mathrm{Xe}$ & 9.15 & 9.14 & 0.0010941 \\
\hline
\end{tabular}

Table 10. Fission yield data used in computations

\begin{tabular}{cccc}
\hline \multirow{2}{*}{ Isotope } & \multicolumn{2}{c}{ Fission yield } & \multirow{2}{*}{ Keviation } \\
& Kedl [14] & Present & Dian \\
\hline${ }^{135} \mathrm{Xe}$ & 0.003 & 0.0018 & 0.6666 \\
${ }^{135} \mathrm{I}+{ }^{135} \mathrm{Te}$ & 0.061 & 0.0615 & 0.00813 \\
\hline
\end{tabular}

Moreover, the analytical model used by Kedl [14] performed calculations by dividing the reactor core into different subsections which carry different importance weights depending on the zone/region of nuclear importance. The calculations relied on parameters derived from the Krypton Experiment, many of which were subject to some subjective interpretation (e.g., mass transfer coefficients). While both calculations were performed with a nominal stripping efficiency of $10 \%$, the authors gave preliminary information regarding the real value being upwards of $10 \%$ towards $50 \%$ to $100 \%$. Moreover, pre-calculations in the critical reactor pointed at poison fractions of approximately $0.3-0.4 \%$, which is well within the range between $10-12 \%$ stripping efficiency, hereby calculated (Table 11). Considering the assumptions made and deviation in experimental nuclear data, it can be said that TRITON is accurately representing the noble gas and metal removal process in the off gas system. 


\section{PARAMETRIC STUDIES}

This section discusses the results of two parametric studies. First, the effect of the gas/liquid separator efficiency on the ${ }^{135} \mathrm{Xe}$ poison fraction, reactivity, and ultimately the lifetime of the fuel salt was analyzed. Then the appropriate number of burnup steps and days was determined to develop a set of best practices that more accurately capture the change in composition over time in all mixtures.

\subsection{GAS/LIQUID SEPARATOR EFFICIENCY}

The poison fraction was investigated further at higher separator efficiencies. It is known that this efficiency is greater than $50 \%$. A parametric study was undertaken by varying this efficiency from 0 to $100 \%$ while keeping all other parameters fixed. After the burnup calculations, the poison fraction was recalculated for each case in SERPENT2. The results are listed in Table 11 and depicted in Figure 9.

\section{Table 11. MSRE ${ }^{135}$ Xe poison fraction at different OGS efficiencies}

\begin{tabular}{cc}
\hline OGS efficiency & ${ }^{135} \mathbf{X e}$ poison fraction \\
\hline 0.05 & 0.01015 \\
0.10 & 0.006027 \\
0.12 & 0.005176 \\
0.15 & 0.004286 \\
0.20 & 0.003324 \\
0.40 & 0.001754 \\
0.60 & 0.00119 \\
0.80 & 0.000901 \\
1.00 & 0.000724 \\
\hline
\end{tabular}

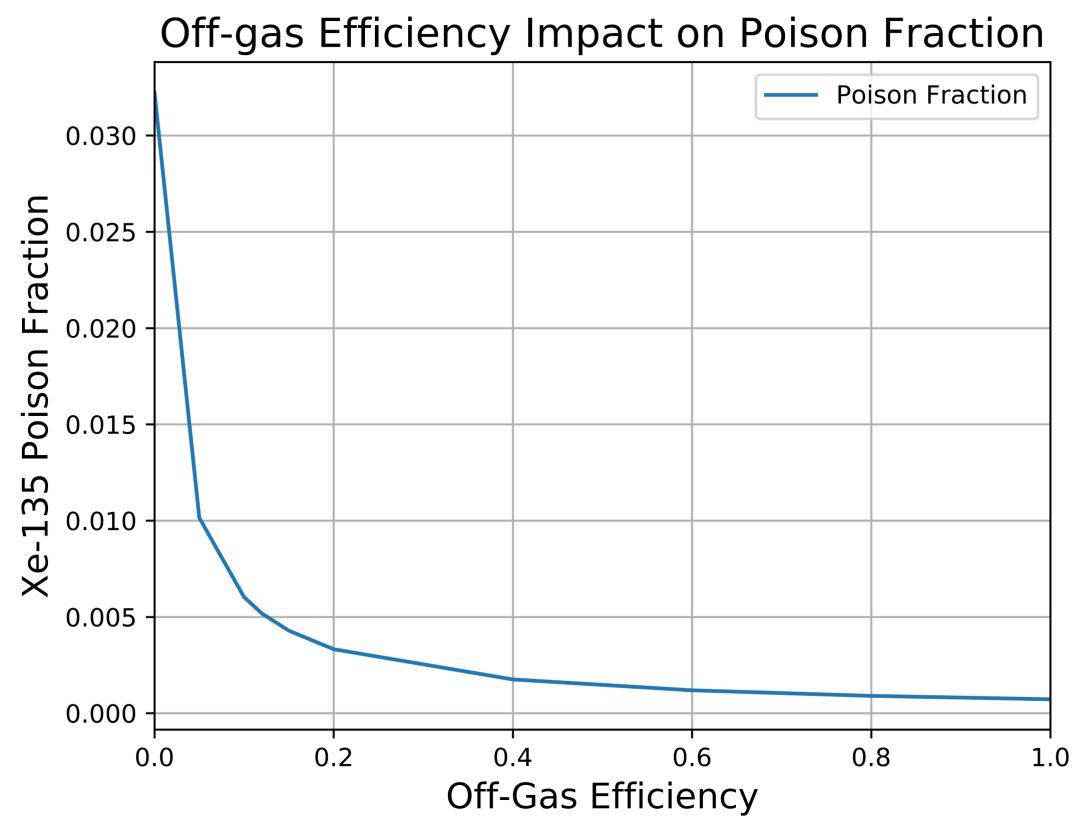

Figure 9. MSRE ${ }^{135} \mathrm{Xe}$ poison fraction as a function of OGS efficiency. 
As expected and shown in Figure 9, the OGS efficiency has a significant, exponential impact on the ${ }^{135} \mathrm{Xe}$ poison fraction. Notice that at $100 \%$ efficiency, the poison fraction is not zero, since there will always be a fraction of xenon in the core due to constant generation. The lower poison fractions are attributed to higher ${ }^{135} \mathrm{Xe}$ concentration in the OGS (Figure 10b) and therefore lower concentrations in the PFL (Figure 10a). The results for the MSBR can be found in Table A-1 and Figure A-2 of Appendix A. Additionally, see Table B-1 and Figure B-2 in Appendix B for the results of the MSDR.

Another way to assess the accuracy of TRITON's results is by analyzing the equilibrium concentration in the PFL and OGS. This is easily done by extracting the information from Mixture 2. In the PFL, the equilibrium is seen to decrease as the OGS efficiency increases. Similar behavior can be seen for the MSBR (Figure A-5a and A-5b of Appendix A) and the MSDR (Figure B-5a and B-5b of Appendix B). These equilibrium concentrations are dependent on each other.

To further analyze the behavior and transportation of isotopes in TRITON, concentrations in the fuel salt can be compared to concentrations in the OGS, ensuring heuristically the correct masses are being transferred. At equilibrium, the change of concentration can be set as a function of time to zero to solve for the generation rate. For any isotope in Mixture 1:

$$
\begin{gathered}
\frac{d N_{1}}{d t}=0=\text { Generation }- \text { Removal } \\
0=G_{1}-\lambda_{e f f} N_{1} \\
G_{1}=\lambda_{e f f} N_{1},
\end{gathered}
$$

and for Mixture 2:

$$
\begin{aligned}
\frac{d N_{2}}{d t} & =\text { Removal } \\
N_{2} & =\lambda_{e f f} N_{1} t \\
N_{1} & =\frac{N_{2}}{\lambda_{e f f} t} \\
G_{2} & =\lambda_{e f f} N_{1},
\end{aligned}
$$

where $G_{1}=G_{2}$. This demonstrates that SCALE is correctly modeling fission product removal for various important fission products. There are some limitations for modeling certain solid fission products, which are discussed in later sections.

\subsection{REACTIVITY AND K-EIGENVALUE}

No feeds of fertile or fissile material were defined in this work. This allowed for the study of some behaviors and improvements that arise from having a variety of fission products removed from the PFL. As 
seen in the previous section, the OGS has a significant impact on the concentration of ${ }^{135} \mathrm{Xe}$ in the PFL. It should be expected to have higher fuel salt lifetimes (higher operation periods), higher fuel utilization, and lower fuel consumption. In terms of nuclear reactor physics parameters, this translates to $k_{\text {inf }}$ decreasing at a lower rate with increasing OGS efficiency. Breeding potential also should increase. The OGS removal efficiency effect in $k_{\text {inf }}$ for the MSRE is depicted in Figure 11. As expected, with higher OGS efficiencies, $k_{\text {inf }}$ decreases less rapidly. Again, this is because high absorbent isotopes are being removed constantly (e.g., ${ }^{135} \mathrm{Xe}$ ). While the difference in $k_{\text {inf }}$ among OGS operating cases might not be noticeable, there is a notable effect on reactivity and on the lifetime extension of the fuel salt. This is important from a fuel utilization perspective and from a safety standpoint.

Figure 12a shows that while changes in efficiency might have an impact on the system's reactivity, it appears to be negligible (maximum $100 \mathrm{pcm}$ ). On the other hand, if the OGS stops operating completely, then there can be insertions of up to $350 \mathrm{pcm}$ (Figure 12b). For larger reactor systems like the MSDR or the MSBR, the effect is more noticeable. For the MSBR, the insertion is more pronounced in both cases: 450 pcm among operating parameters and $\approx 1,785 \mathrm{pcm}$ in the case of complete shutdown of the OGS (see Figure A-4a and A- $4 \mathrm{~b}$ of Appendix A). For the MSDR, there is a negligible $\approx 85 \mathrm{pcm}$ maximum insertion among operating parameters, but there is a $450 \mathrm{pcm}$ insertion in scenarios of OGS failure (see Figure B-4a and B-4b of Appendix B). The higher reactivity insertions that are possible in both the MSBR and the MSDR are due to the higher fuel salt inventory, as these systems are larger. This demonstrates the importance of having a reliable OGS.

In terms of fuel utilization and fuel salt lifetime, the OGS provides valuable benefits in all three systems. Extraction of neutron absorbent isotopes allows for an increase capture fraction in fissile and fertile material. Preliminary calculations show that the fuel salt lifetime is extended by $10.73 \%$ (approximately 64.44 days), $2.60 \%$ (approximately 15 days) and 7.46\% (approximately 42 days) for the MSRE, MSBR and MSDR, respectively, by just having a nominal OGS efficiency of 10\%. The MSRE is seen to reach equilibrium starting at an OGS efficiency of $40 \%$. As for the MSBR and MSDR, the equilibriums start at an OGS efficiency of $20 \%$. These values are conservative, since in reality the efficiencies are known to be even higher. Full results for the operating parameter space are shown in Table 12 through 14 and are depicted in Figure 13. Not only does the OGS bring benefits in terms of neutron economy, but it also benefits plant economy, as it allows more energy to be extracted for the same amount of fuel.

Table 12. MSRE fuel lifetime improvement as a function of OGS efficiencies

\begin{tabular}{cc}
\hline OGS efficiency & Fuel salt lifetime improvement \\
\hline 0.00 & 0.0000 \\
0.05 & 0.0640 \\
0.10 & 0.1073 \\
0.12 & 0.1163 \\
0.15 & 0.1260 \\
0.20 & 0.1365 \\
0.40 & 0.1538 \\
0.60 & 0.1600 \\
0.80 & 0.1632 \\
1.00 & 0.1651 \\
\hline
\end{tabular}


Table 13. MSBR fuel lifetime improvement as a function of OGS efficiencies

\begin{tabular}{cc}
\hline OGS efficiency & Fuel salt lifetime improvement \\
\hline 0.00 & 0.0000 \\
0.05 & 0.0133 \\
0.10 & 0.0267 \\
0.12 & 0.0293 \\
0.15 & 0.0320 \\
0.20 & 0.0349 \\
0.40 & 0.0395 \\
0.60 & 0.0411 \\
0.80 & 0.0420 \\
1.00 & 0.0425 \\
\hline
\end{tabular}

Table 14. MSDR fuel lifetime improvement as a function of OGS efficiencies

\begin{tabular}{cc}
\hline OGS efficiency & Fuel salt lifetime improvement \\
\hline 0.00 & 0.0000 \\
0.05 & 0.0601 \\
0.10 & 0.0746 \\
0.12 & 0.0773 \\
0.15 & 0.0801 \\
0.20 & 0.0830 \\
0.40 & 0.0876 \\
0.60 & 0.0892 \\
0.80 & 0.0901 \\
1.00 & 0.0905 \\
\hline
\end{tabular}




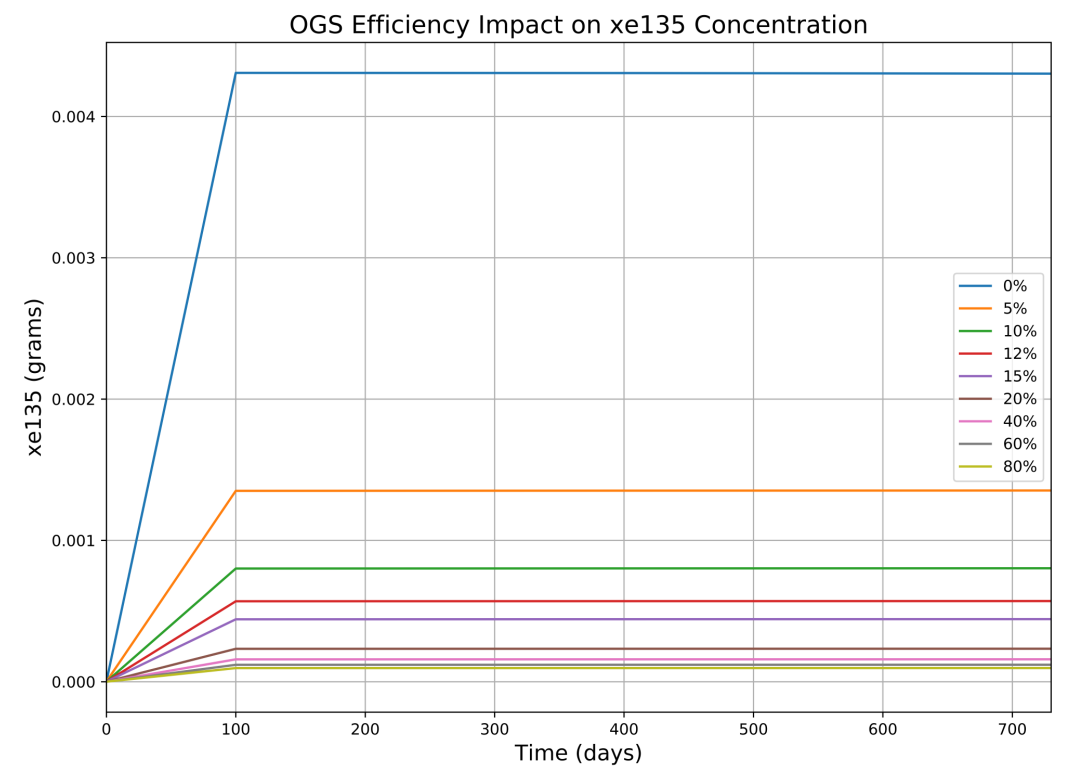

(a)

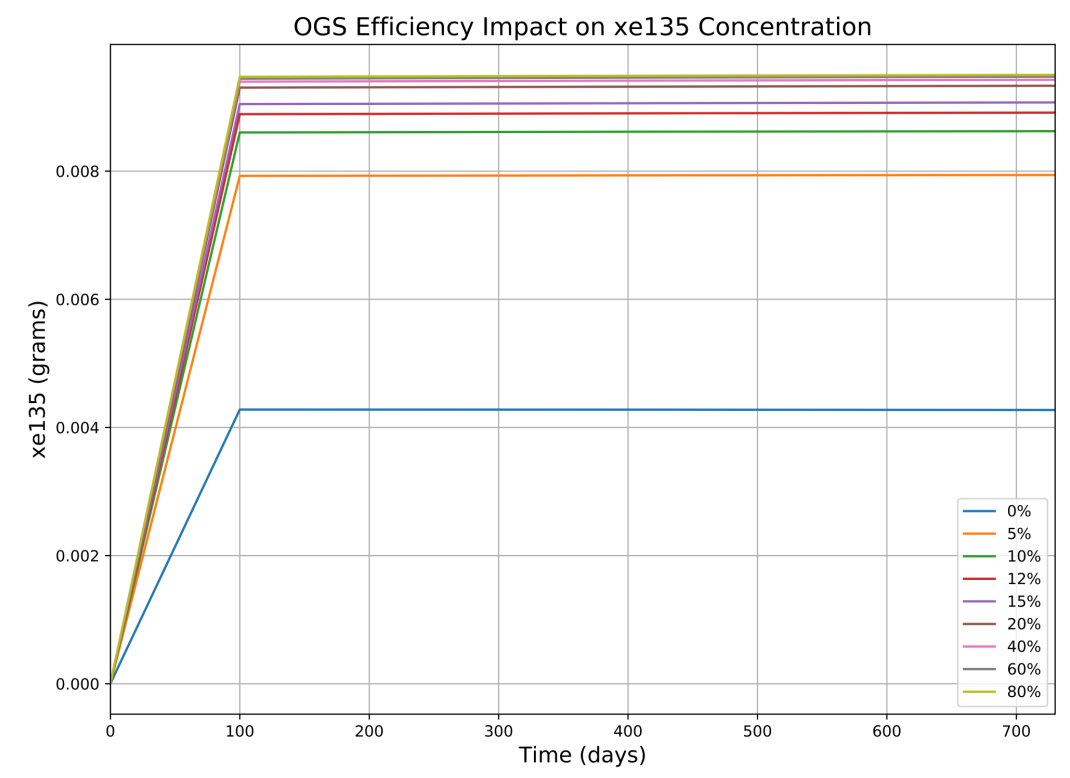

(b)

Figure 10. MSRE ${ }^{135} \mathrm{Xe}$ concentration (a) in the OGS and (b) in the PFL. 


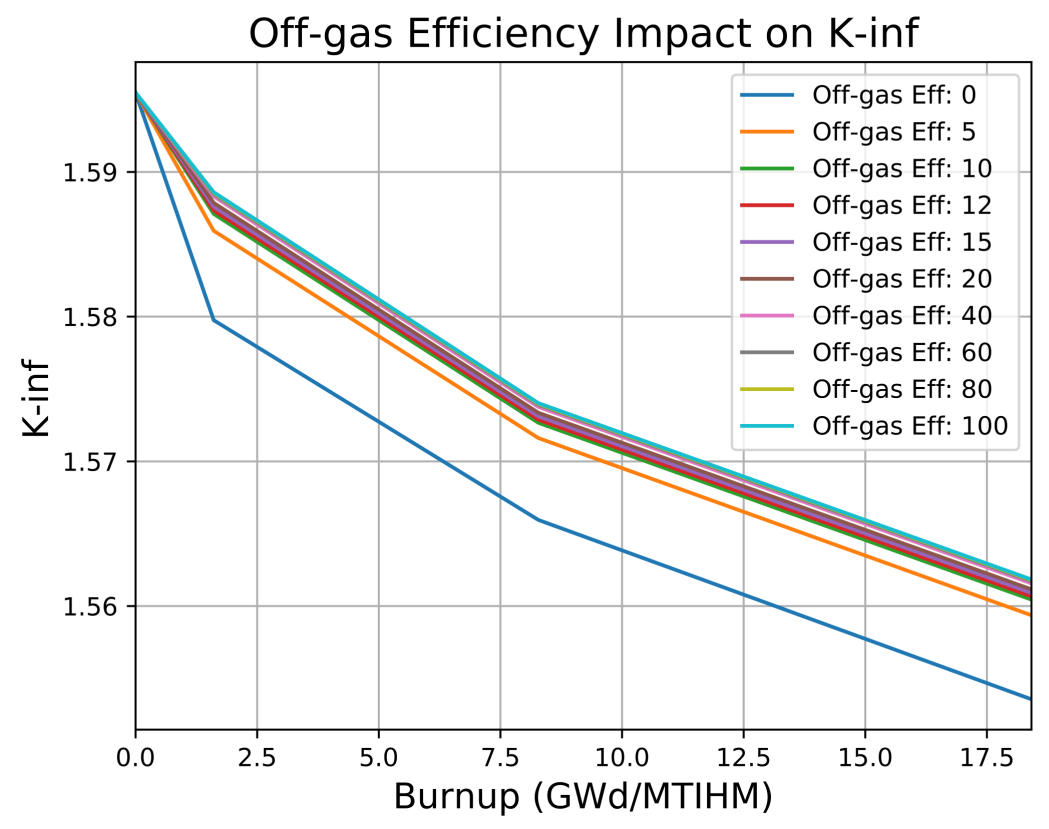

Figure 11. MSRE $k_{\infty}$ as a function of OGS efficiency. 


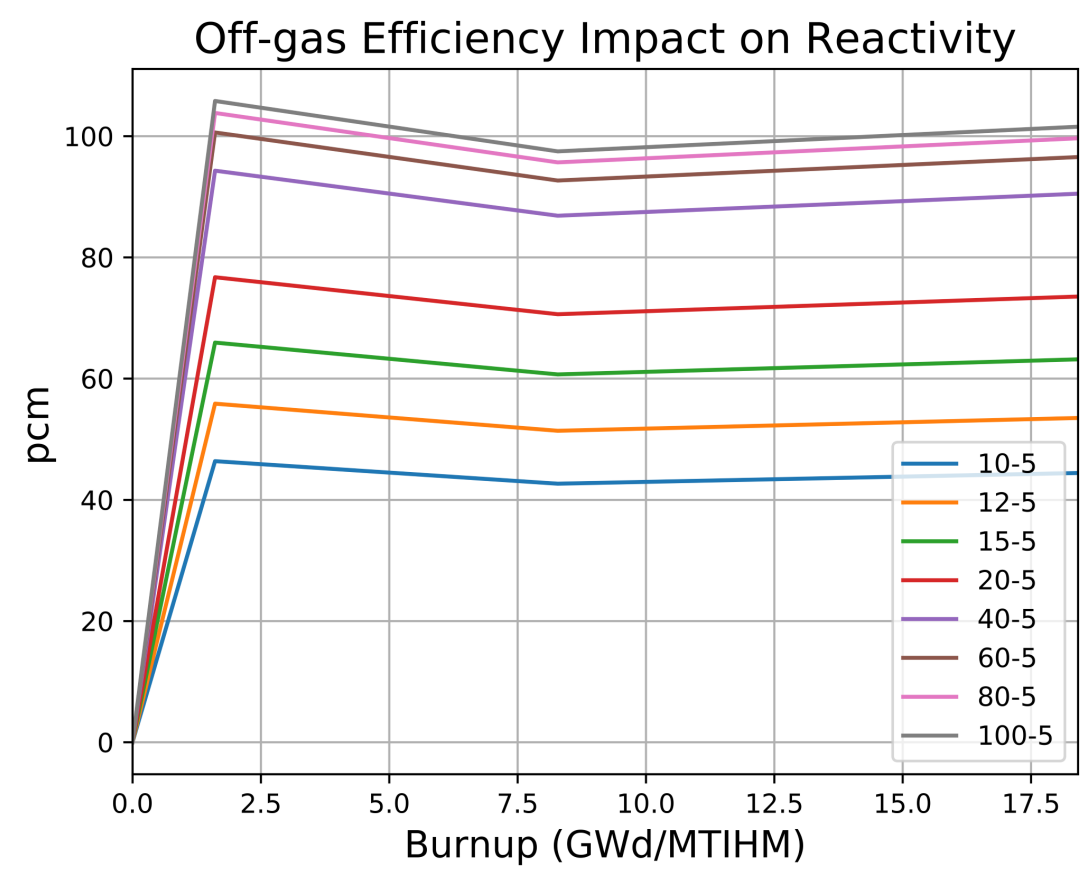

(a)

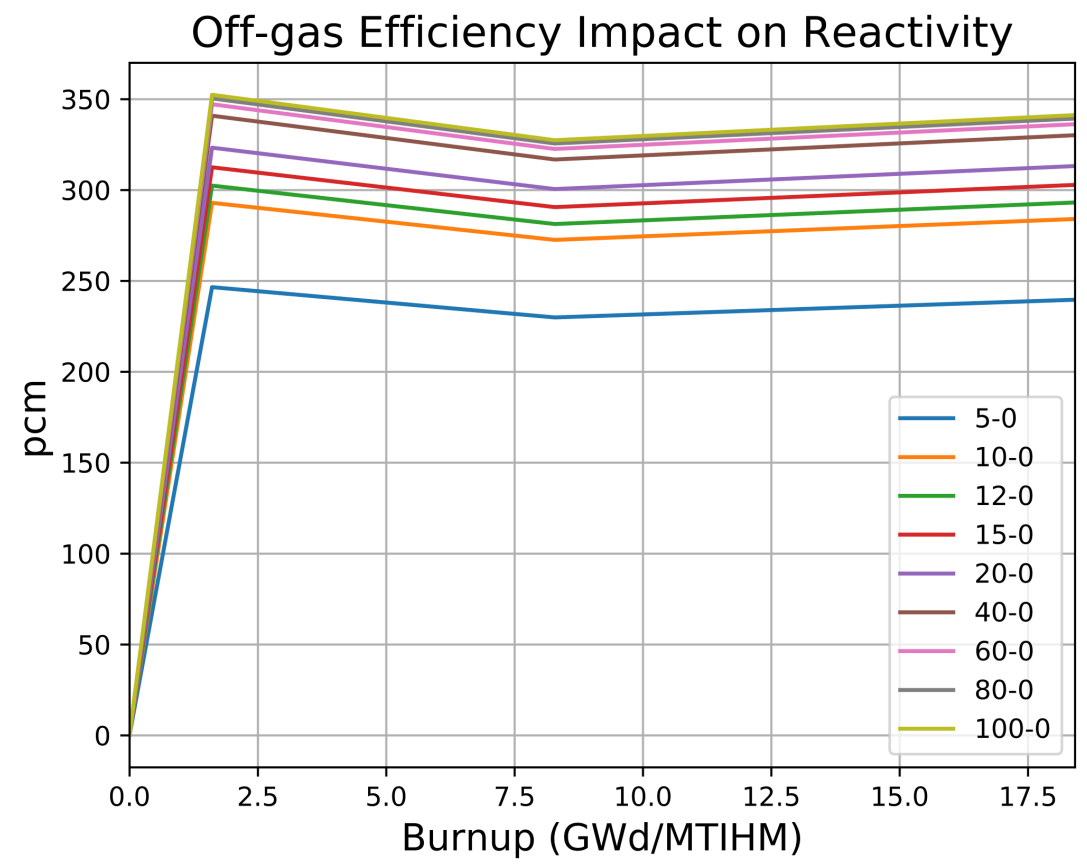

(b)

Figure 12. MSRE OGS efficiency impact on reactivity while in (a) operation and (b) turned on/off. 


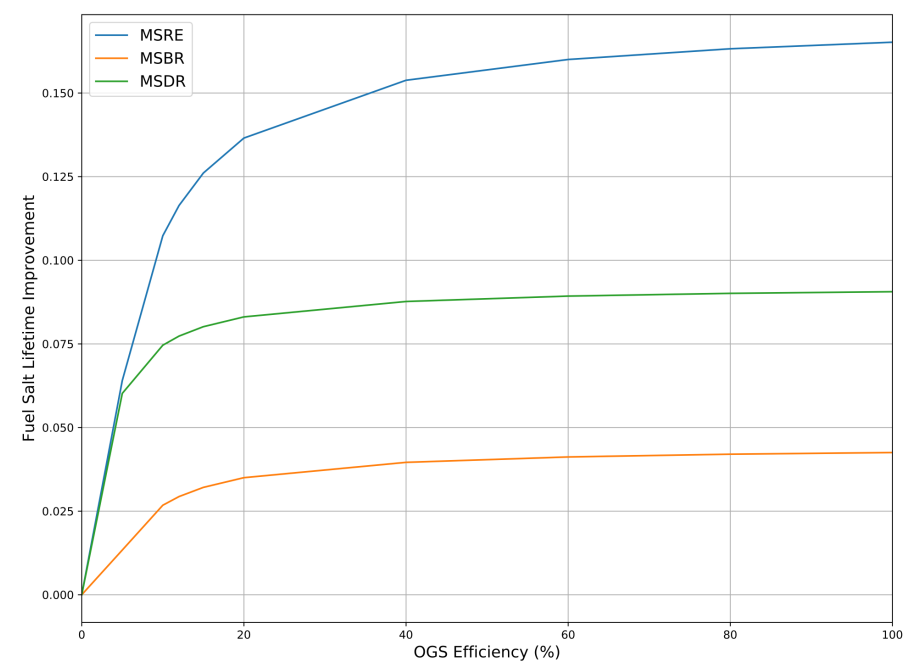

Figure 13. MSR fuel lifetime enhancement as a function of OGS efficiency. 


\section{CONCLUSION}

This work demonstrates the new feed and removal SCALE/TRITON capabilities by modeling three MSR systems and simulating their respective online feed and removal processes. This new tool has been successfully verified and validated using data from the MSRE Krypton Experiment. The analytical model derived by Kedl [14] calculated a ${ }^{135} \mathrm{Xe}$ poison fraction of $0.56 \%$. This provided a target poison fraction for the present model for comparison. After running burnup calculations, the new model predicted a ${ }^{135} \mathrm{Xe}$ poison fraction of $0.60 \%$, which corresponds to a $\approx 7 \%$ deviation from the Kedl's models. Considering the uncertainties that arose during the experiment and derivation of the mass transfer coefficients, as well as the use of different fundamental isotopic data (including different fission yields, decay constants, and therefore generation rates), this work provides confidence that the mismatch in calculated poison fractions can be attributed to these issues rather than a modeling error in reactor operations and online processing phenomena. Furthermore, transport of radionuclides were corroborated with heuristic models that confirm TRITON's results. Preliminary calculations regarding the MSRE suggested a poison fraction of $\approx 0.3-0.4 \%$, which is well within the range of calculated poison fractions for the $\approx 10-12 \%$ OGS efficiency cases. In any case, the values calculated herein are conservative since the actual stripping efficiency is known to be greater than $50 \%$. The parametric studies revealed that careful consideration must be taken when designing the OGSs due to their impact on system reactivity. This means that systems must be designed to reliably address all steps of removal, storage, transportation, and disposal. The OGS also provides benefits by allowing higher breeding ratios, longer fuel salt lifetime, and therefore higher utilization of fuel resources, obtaining more energy from the same initial fuel amount. Future work includes modeling different complex systems independently as different mixtures with different removal and feed rates to validate the well-mixed salt model. Future efforts also includes benchmarking to other MSR tools. Furthermore, testing the new capabilities in two-fluid systems and time-dependent removal rates could provide useful insights into future MSR operating scenarios. 


\section{REFERENCES}

[1] A. Ahmad, E. B. McClamrock, and A. Glaser. Neutronics Calculations for Denatured Molten Salt Reactors: Assessing Resource Requirements and Proliferation-Risk Attributes. Annals of Nuclear Energy, 75:261-267, 2015.

[2] M. Aufiero, A. Cammi, et al. An Extended Version of the SERPENT-2 Code to Investigate Fuel Burn-Up and Core Material Evolution of the Molten Salt Fast Reactor. Journal of Nuclear Materials, 441:473-486, 2013.

[3] H. F. Bauman, G. W. Cunningham III, et al. ROD: A Nuclear and Fuel-Cycle Analysis Code for Circulating-Fuel Reactors. Technical Report ORNL-TM-3359, Oak Ridge National Laboratory, 1971.

[4] E. S. Bettis, L. G. Alexander, and H. L. Watts. Design Studies of a Molten Salt Reactor Demonstration Plant. Technical Report ORNL-TM-3832, Oak Ridge National Laboratory, 1972.

[5] B. R. Betzler, J. J. Powers, and A. Worrall. Molten Salt Reactor Neutronics and Fuel Cycle Modeling and Simulation with SCALE. Annals of Nuclear Energy, 101:489-503, 2017.

[6] S. M. Bowman. SCALE 6: Comprehensive Nuclear Safety Analysis Code System. Nuclear Technology, 174, 2011.

[7] S. Brinton. The Advanced Nuclear Industry. http://www.thirdway.org/report/the-advanced-nuclear-industry. Third Way (June 2015), Accessed March 1, 2016.

[8] M. B. Chadwick, P. Oblozinky, et al. ENDF/B-VII.1: Nuclear Data For Science and Technology: Cross Sections, Covariance, Fission Product Yields and Decay Data. Nuclear Data Sheets, 112:2887-2996, 2011.

[9] I. C. Gauld, G. Radulescu, et al. Isotopic Depletion and Decay Methods and Analysis Capabilities in SCALE. Nuclear Technology, 174:267-283, 2011.

[10] S. Goluoglu, L. M. Petrie Jr., et al. Monte Carlo Criticality Methods and Analysis Capabilities in SCALE. Nuclear Technology, 174:214-235, 2011.

[11] M. S. Greenwood, B. R. Betzler, and L. Qualls. Dynamic Systems Models for Informing Licensing Safeguards Investigations of Molten Salt Reactors. Technical Report ORNL/TM-2018/876, Oak Ridge National Laboratory, 2018.

[12] D. Heuer, E. Merle-Lucotte, et al. Towards the Thorium Fuel Cycle with Molten Salt Reactors. Annals of Nuclear Energy, 64:421-429, 2014.

[13] D. Heuer, E. Merle-Lucotte, et al. Simulation Tools and New Developments of the Molten Salt Fast Reactor. In Proc. of the European Nuclear Conference ENC2010. Barcelona, Spain, 2019.

[14] R. J. Kedl and A. Houtzeel. Development of a Model for Computing Xe-135 Migration in the MSRE. Technical Report ORNL-4069, Oak Ridge National Laboratory, 1967.

[15] Jaakko Leppänen. The Serpent Monte Carlo code: Status, development and applications in 2013. Annals of Nuclear Energy, 82, 2015. 
[16] A. Nuttin, D. Heuer, et al. Potential of thorium molten salt reactors detailed calculations and concept evolution with a view to large scale energy production. Progress in Nuclear Energy, 46:77-99, 5005.

[17] J. Park, Y. Jeong, et al. Whole Core Analysis of Molten Salt Breeder Reactor with Online Fuel Reprocessing. International Journal of Energy Research, 39:1673-1680, 2015.

[18] R. C. Robertson. MSRE Design and Operations Report Part I Description of Reactor Design. Technical Report ORNL-TM-728, Oak Ridge National Laboratory, 1965.

[19] R. C. Robertson. Conceptual Design Study of a Single-Fluid Molten-Salt Breeder Reactor. Technical Report ORNL-4541, Oak Ridge National Laboratory, 1971.

[20] M. W. Rosenthal. An Account of Oak Ridge National LaboratoryâĂŹs Thirteen Nuclear Reactors. Technical Report ORNL/TM-2009/181, Oak Ridge National Laboratory, 2010.

[21] A. Rykhlevskii, B. R. Betzler, A. Worrall, and K. D. Huff. Fuel Cycle Performance of Fast Spectrum Molten Salt Reactor Designs. In Proc. Int. Conf. on Mathematics and Computational Methods Applied to Nuclear Science and Engineering (MESC 2019). Portland, OR, 2019.

[22] R. J. Sheu, C. H. Chang, et al. Depletion Analysis on Long-Term Operation of the Conceptual Molten Salt Actinide Recycler \& Transmuter (MOSART) by Using a Special Sequence Based on SCALE6/TRITON. Annals of Nuclear Energy, 53:1-8, 2013. 
APPENDIX A. MODELING AND SIMULATION RESULTS FOR THE MSBR 



\title{
APPENDIX A. MODELING AND SIMULATION RESULTS FOR THE MSBR
}

\author{
Molten Salt Breeder Reactor
}

This section presents some results for the MSBR using the same methodology developed for the MSRE. This section provides a brief overview of the results obtained for the MSBR case. As in previous sections, this analysis begins with validation of the unit cell models. The full core spectrum comparison is presented above and is not repeated here. The flux spectrum from the unit cell in SCALE and in SERPENT2 are compared in Figure B-1. It can be observed that both distributions match adequately.

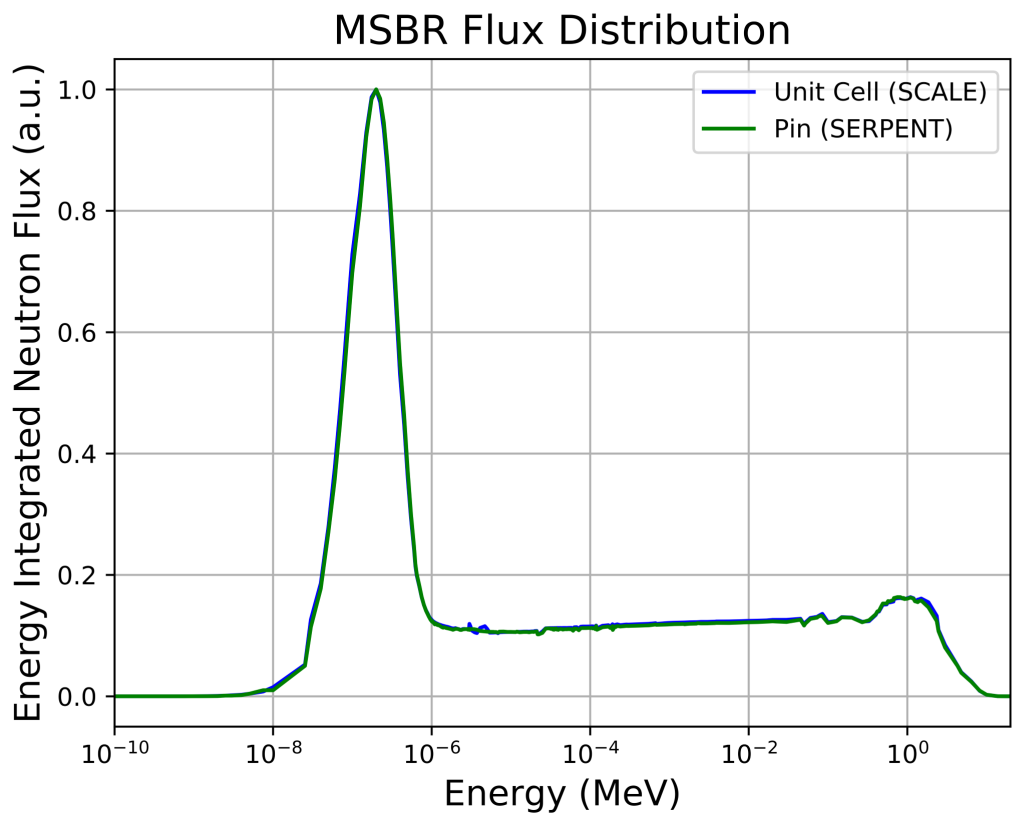

Figure A-1. MSBR SCALE and SERPENT2 flux spectrum comparison.

The ${ }^{135} \mathrm{Xe}$ poison fraction behaves exponentially as a function of the OGS efficiency as expected (Figure A-2). A more detailed explanation is available in the main body of this document. The values for the poison fraction at different efficiencies are given in Table A-1. The MSBR results differ significantly from those obtained by Kedl [14] and for the MSRE and MSDR [19]. These discrepancies are likely due to the approximations and assumptions made regarding reactor core geometry. The MSBR core design is more complex than the other two systems. While the molten salt fuel channels are cylindrical in all three designs, the diameter varies, depending on their location in the axial and radial direction of the core. This variation results in some inaccuracies and biases that might require correction, especially in the unit cell model approximation.

The reactivity, $k_{e f f}$, is impacted by a variety of high absorption cross section elements, including some isotopes of xenon, gadolinium, samarium, and cadmium, among others. This study included a parametric study to quantify the effect of xenon removal on the reactivity value. A high-level plot of the OGS efficiency's impact on $k_{e f f}$ reveals that there is a significant impact (Figure A-3). This has implications in terms of reactivity and lifetime of the fuel salt.

The reactivity insertions among OGS efficiencies were calculated in two scenarios: (1) among operating 
Table A-1. MSBR poison fraction at different OGS efficiencies

\begin{tabular}{cc}
\hline OGS efficiency & Xenon poison fraction \\
\hline 0.05 & 0.10611 \\
0.10 & 0.06077 \\
0.12 & 0.05195 \\
0.15 & 0.00428 \\
0.20 & 0.03281 \\
0.40 & 0.01705 \\
0.60 & 0.01152 \\
0.80 & 0.00872 \\
1.00 & 0.00698
\end{tabular}

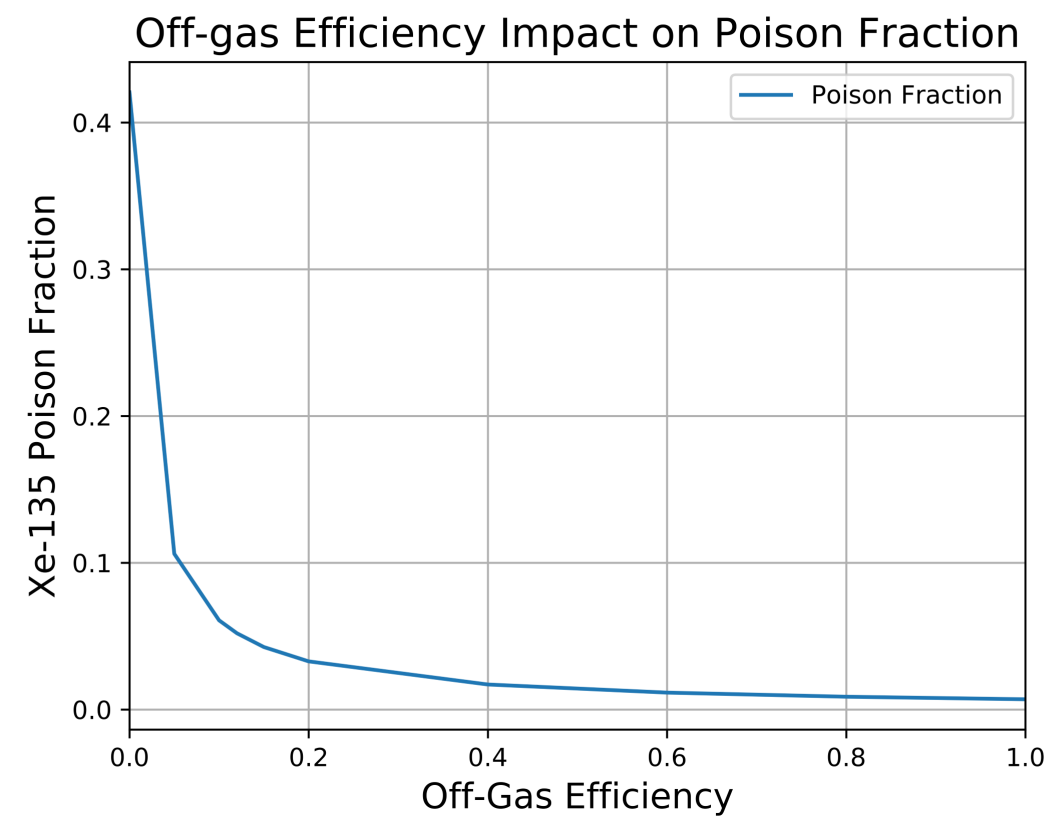

Figure A-2. MSBR poison fraction as a function of OGS efficiency.

parameters taking 5\% as the baseline, and (2) in the case of OGS shutdown. It was found that the impact among OGS efficiencies is significant in certain reactor models and operating conditions. For variation in operating conditions, the reactivity insertions reach a maximum of about $\approx 500 \mathrm{pcm}$ in the worst case scenario. In the case of OGS shutdown, preliminary calculations indicate that reactivities up to $1,700 \mathrm{pcm}$ can occur. The concentration of ${ }^{135} \mathrm{Xe}$ can be seen to vary with OGS efficiency in both the PFL and the OGS in Figures A-5a and A-5b, respectively. In terms of fuel utilization and fuel salt lifetime due to the extraction of neutron absorbent isotopes, the OGS allows a $2.6 \%(\approx 15$ days) extension using a nominal efficiency of $10 \%$. The equilibrium is seen to be reached at around $20 \%$ OGS efficiency. This results in higher fuel utilization. 


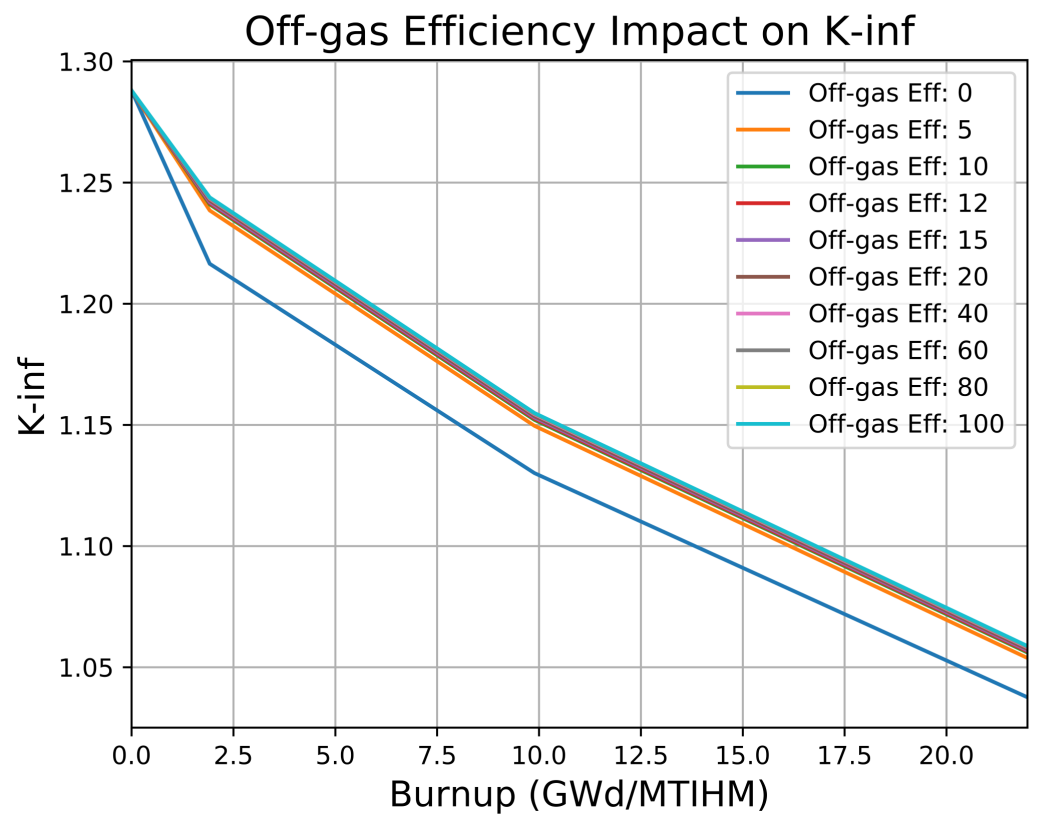

Figure A-3. $K_{\text {inf }}$ as a function of OGS efficiency in the MSBR. 


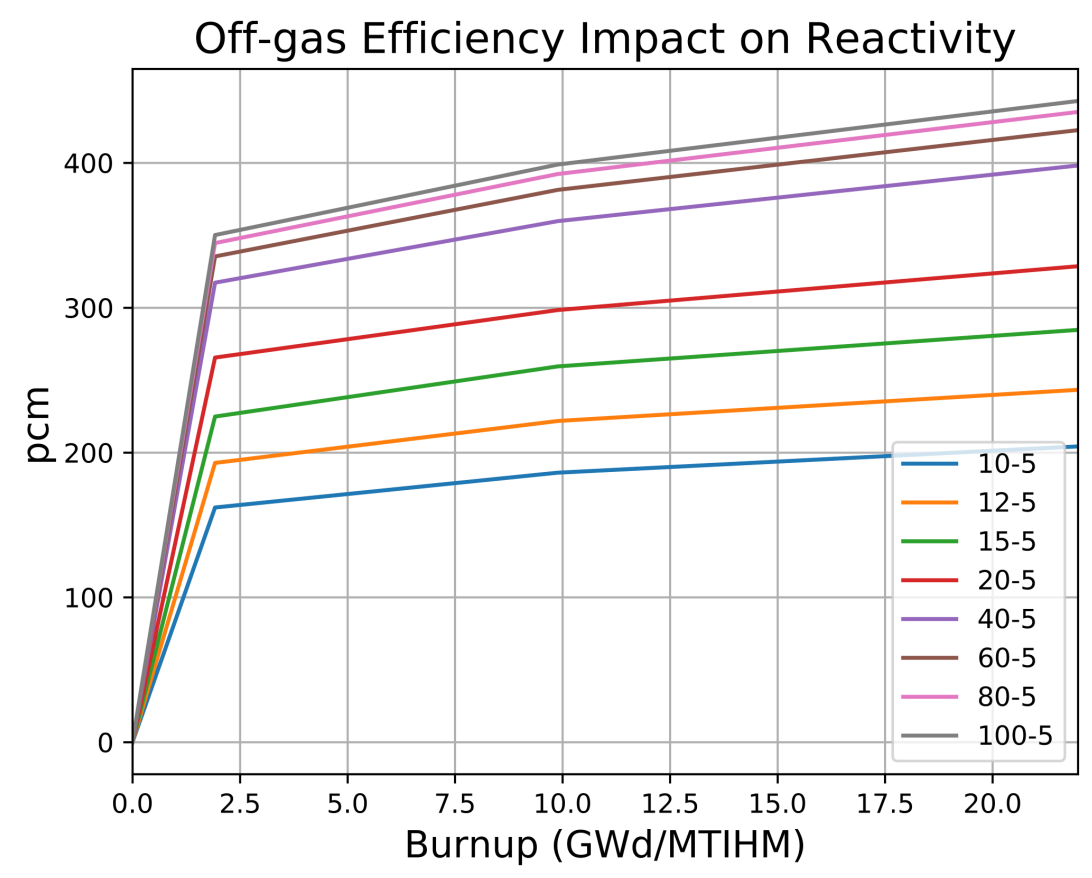

(a)

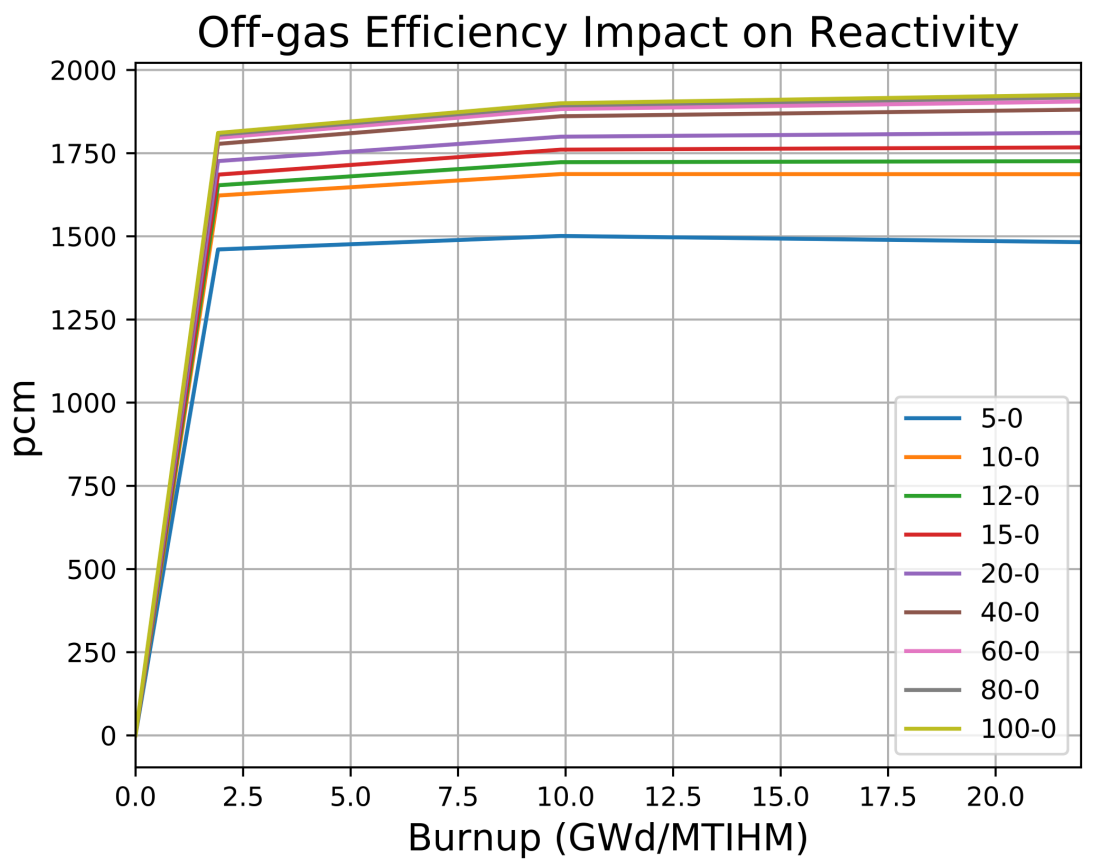

(b)

Figure A-4. OGS efficiency impact on reactivity while in (a) operation and (b) turned on/off. 


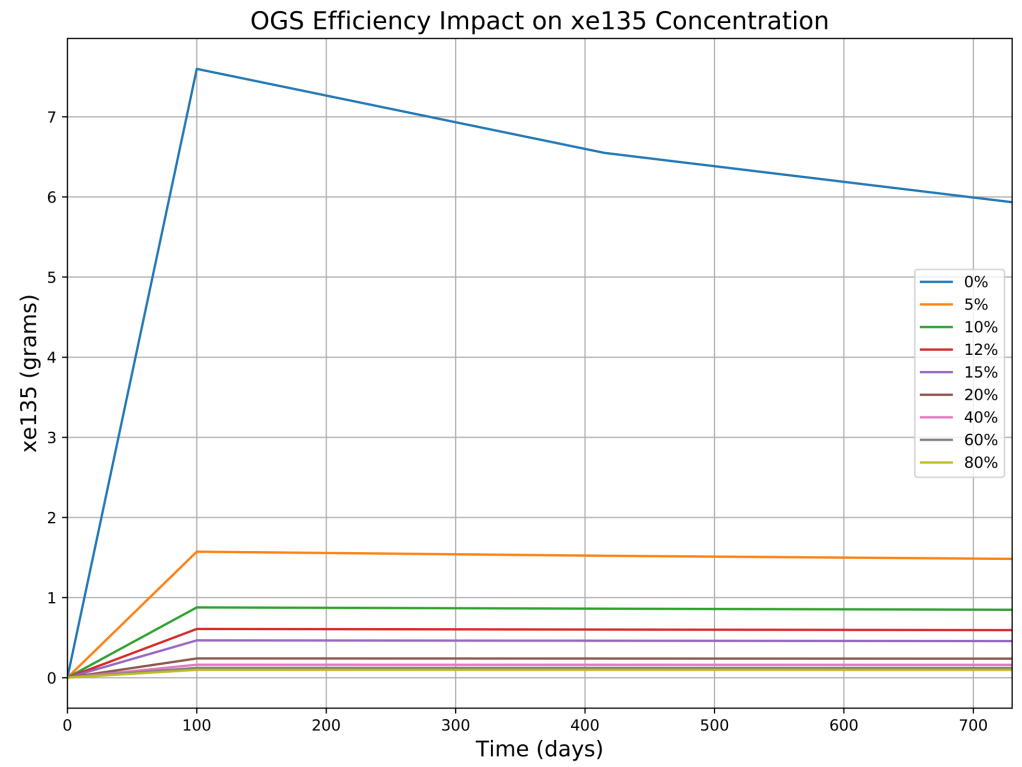

(a)

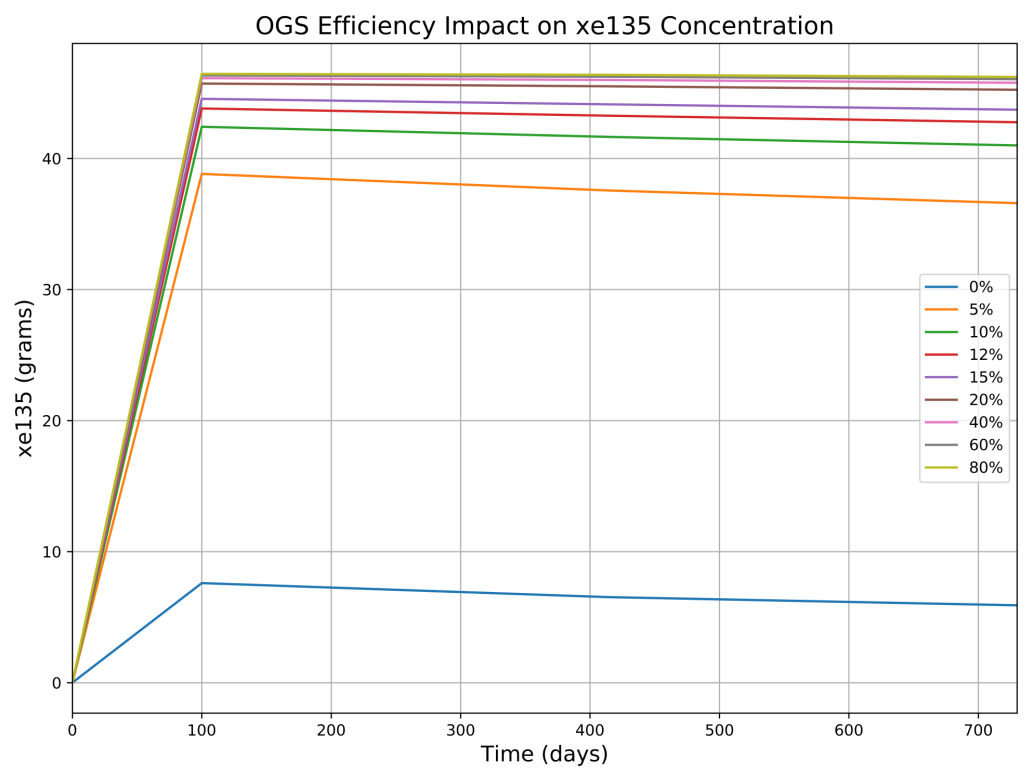

(b)

Figure A-5. ${ }^{135}$ Xe concentration in (a) the OGS and (b) in the PFL. 
APPENDIX B. MODELING AND SIMULATION RESULTS FOR THE MSDR 


\section{APPENDIX B. MODELING AND SIMULATION RESULTS FOR THE MSDR}

This section presents results for the MSDR using the same methodology that was used for the MSRE, so some explanations repeat what was provided in the main text. These results provide a brief explanation for the MSDR case. To validate the unit cell model for the MSDR, the flux spectrum from the unit cell and the full core model were compared (Figure B-1). The flux spectrum for the MSDR core is seen to divert at high energies due to the difference in graphite mass between the full core model and the unit cell which impacts the neutron detector counts.

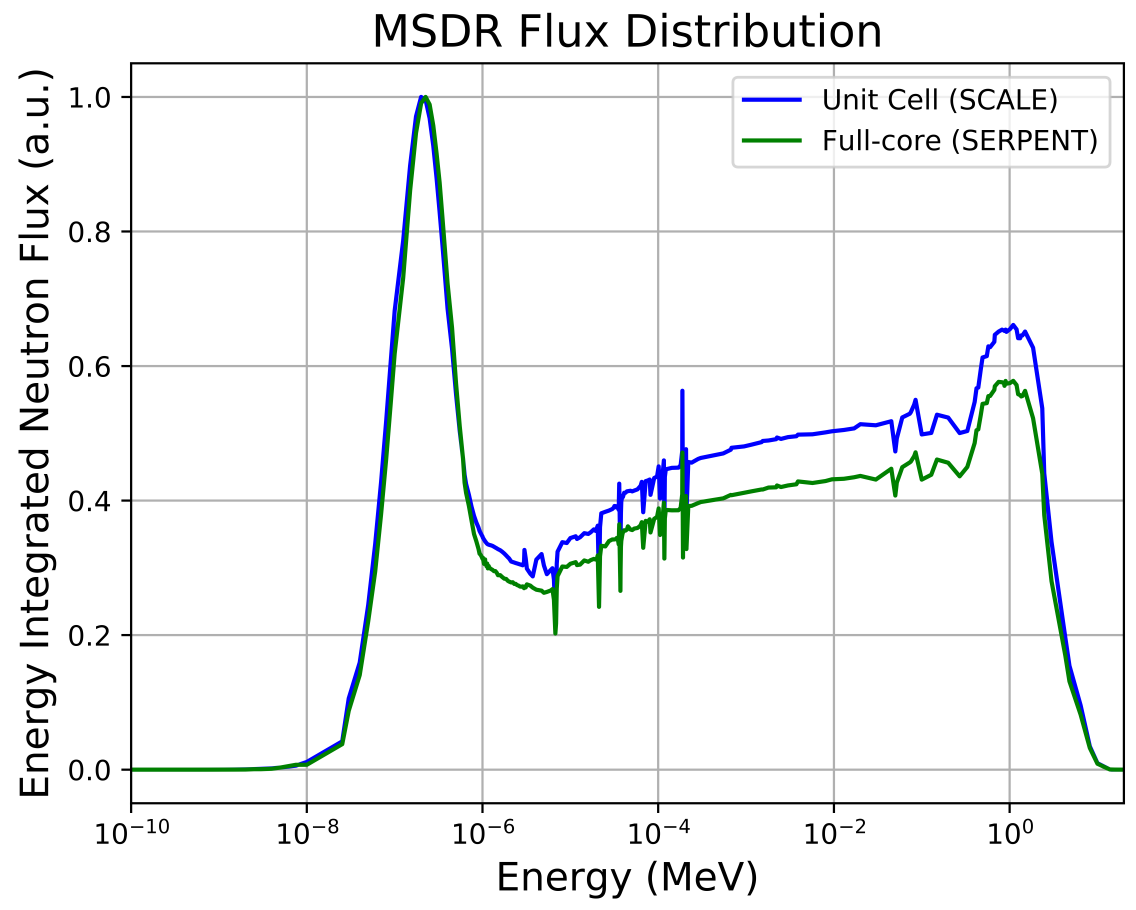

Figure B-1. MSDR SCALE and SERPENT2 flux spectrum comparison.

The poison fraction as a function of the OGS efficiency behaves as expected. The efficiency has an almost exponential impact on the ${ }^{135} \mathrm{Xe}$ poison fraction (Figure B-2). The body of this document provides a detailed explanation. The values for the poison fraction at different efficiencies are given in Table B-1. The MSDR design contains three PFLs, all of which have primary fuel pump bypass lines and higher flow rates. This allows the MSDR concept to achieve lower poison fractions at the same nominal gas/separator efficiency $(\approx 10 \%)$. This is an improvement to the MSRE design. 
Table B-1. MSDR poison fraction at different OGS efficiencies

\begin{tabular}{cc}
\hline OGS efficiency & Xenon poison fraction \\
\hline 0.05 & 0.006635 \\
0.10 & 0.003654 \\
0.12 & 0.003110 \\
0.15 & 0.002532 \\
0.20 & 0.001931 \\
0.40 & 0.000994 \\
0.60 & 0.000669 \\
0.80 & 0.000505 \\
1.00 & 0.000404
\end{tabular}

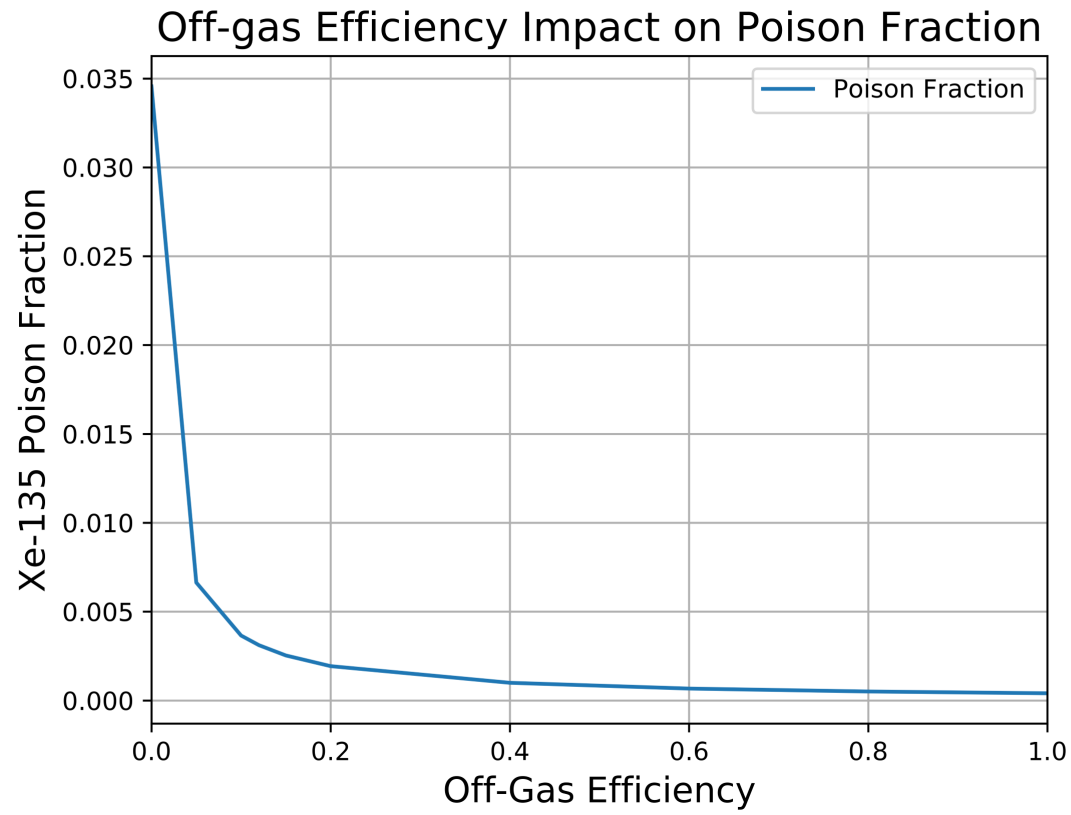

Figure B-2. MSDR poison fraction as a function of OGS efficiency.

The reactivity eigenvalue is affected by a variety of high absorbing fission products. This study quantified the effect of xenon removal by means of the OGS on the reactivity value. A high-level picture of the OGS efficiency's impact on reactivity (Figure B-3) shows a significant impact.

While it is not apparent at first, the impact among OGS efficiencies is significant in some reactor models and under some operating conditions. In the case of the MSDR, reactivity can vary up to $\approx 500 \mathrm{pcm}$ if the OGS suddenly goes offline. For operating condition variations, this effect is less pronounced, reaching $\approx 100 \mathrm{pcm}$ in the worst-case scenario. The concentration of ${ }^{135} \mathrm{Xe}$ can be seen to vary with OGS efficiency in both the PFL and the OGS in Figures B-5a and B-5b, respectively. In terms of fuel utilization and lifetime, the OGS at a nominal efficiency of $10 \%$, allows for a $7.46 \%$ (approximately 42 days) extension. 


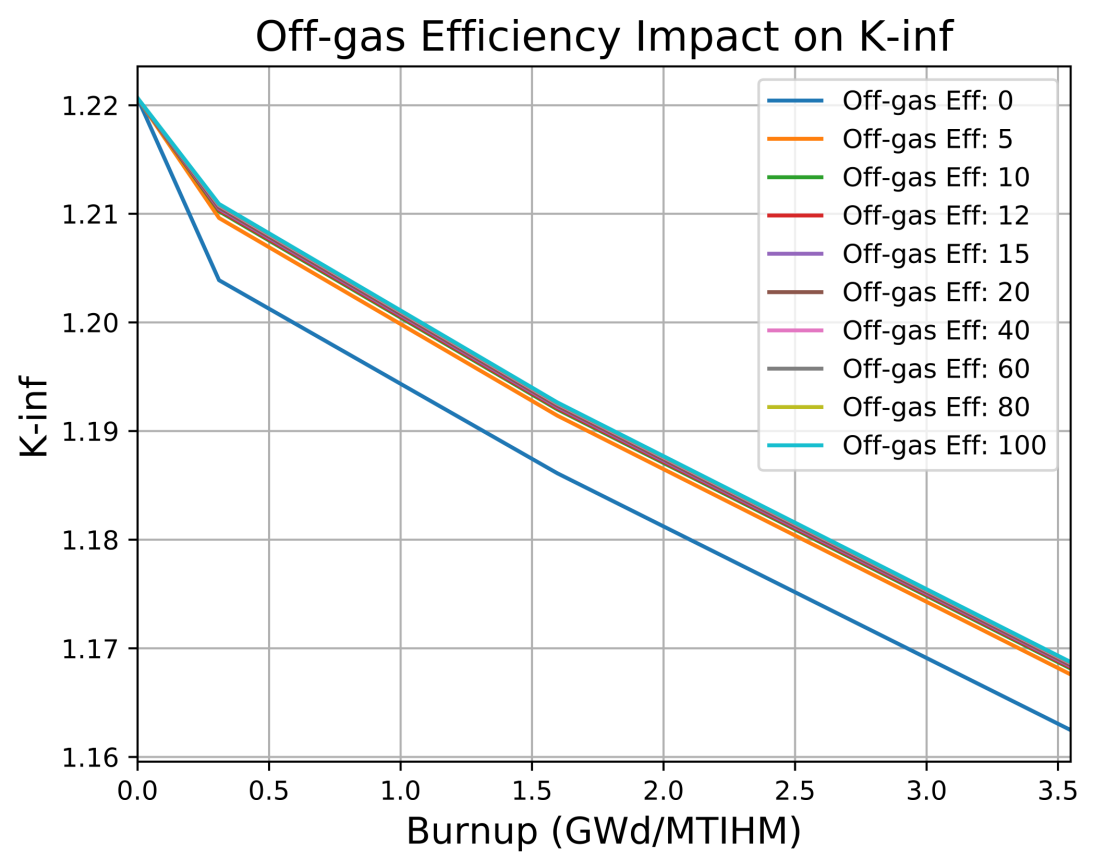

Figure B-3. $K_{\text {inf }}$ as a function of OGS efficiency in the MSDR. 


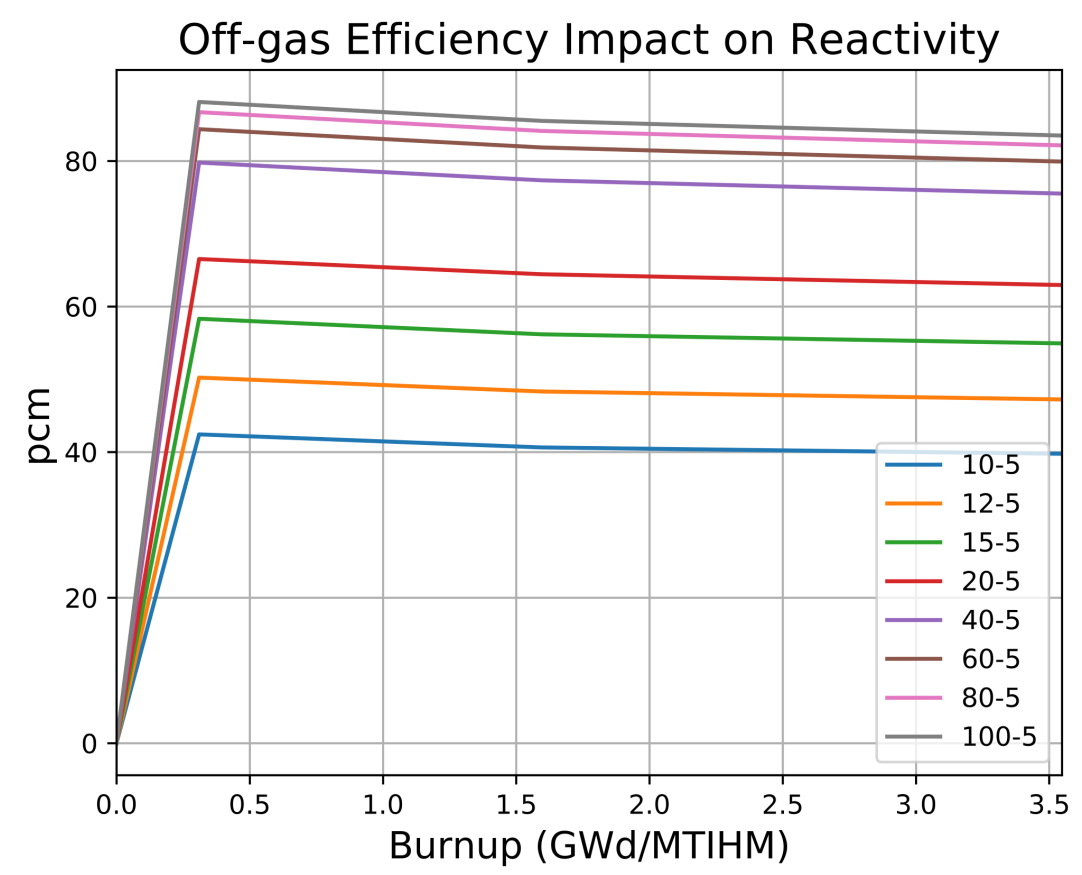

(a)

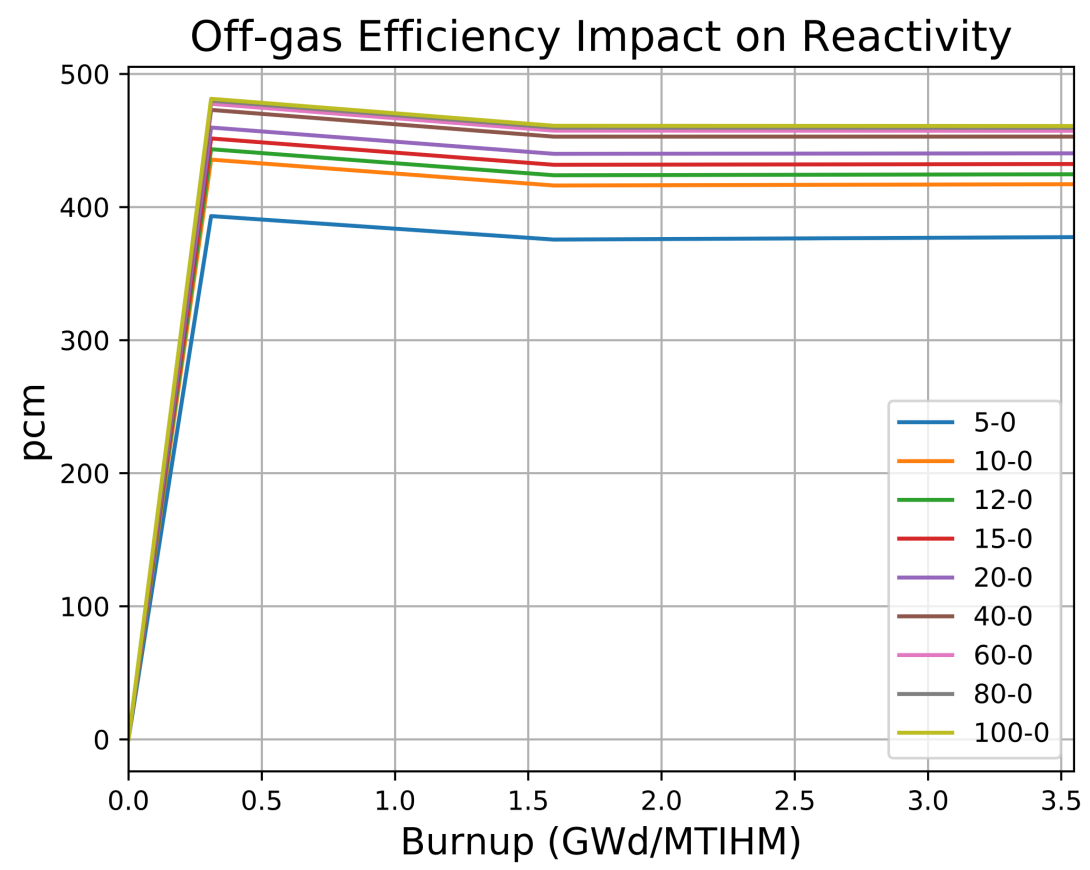

(b)

Figure B-4. OGS efficiency impact on reactivity while in (a) operation and (b) turned on/off. 


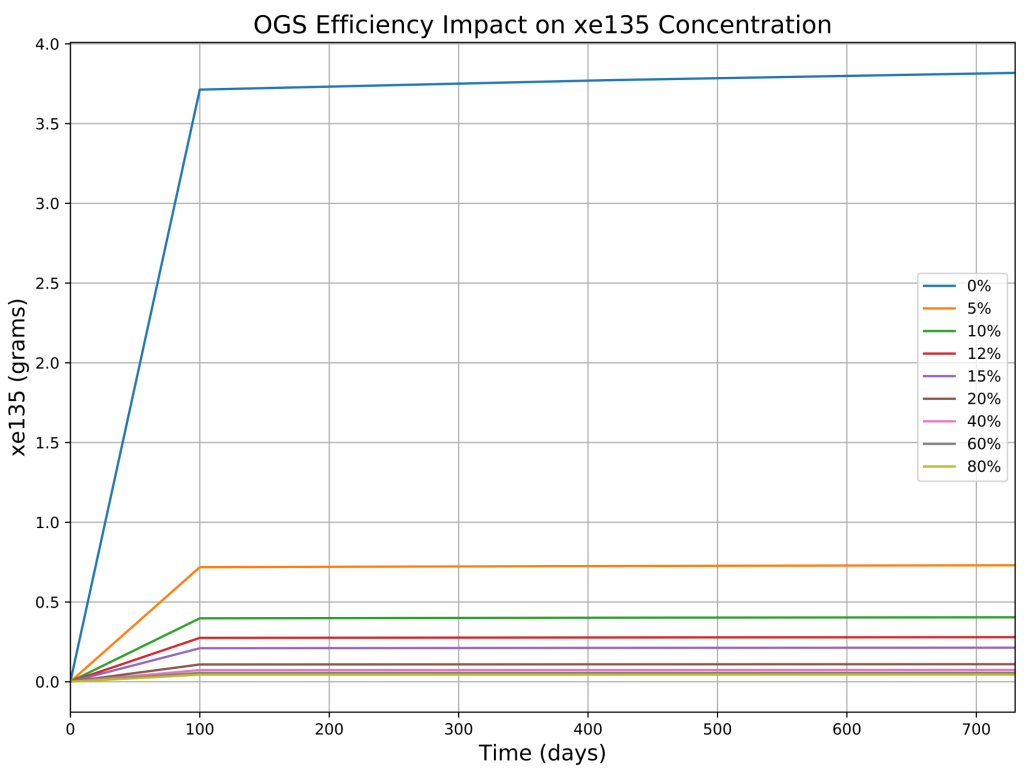

(a)

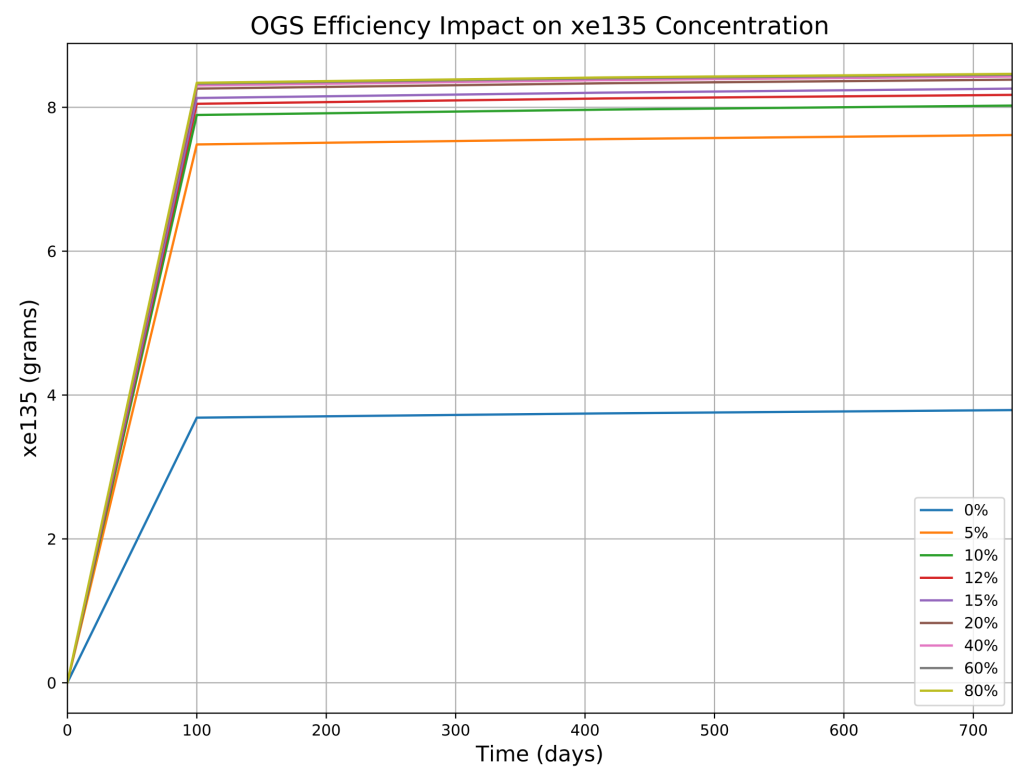

(b)

Figure B-5. ${ }^{135}$ Xe concentration in (a) the OGS and (b) the PFL. 